\title{
A Progress Review on Soot Experiments and Modeling in the Engine Combustion Network (ECN)
}

\author{
Scott A. Skeen, Julien Manin, and Lyle M. Pickett \\ Sandia National Laboratories \\ Emre Cenker \\ King Abdullah University of Science and Technology \\ Gilles Bruneaux \\ IFPEN \\ Katsufumi Kondo and Tets Aizawa \\ Meiji University \\ Fredrik Westlye, Kristine Dalen, and Anders Ivarsson \\ Technical University of Denmark \\ Tiemin Xuan and Jose M Garcia-Oliver \\ Universitat Politecnica de Valencia \\ Yuanjiang Pei and Sibendu Som \\ Argonne National Laboratory \\ Wang Hu and Rolf D. Reitz \\ University of Wisconsin \\ Tommaso Lucchini and Gianluca D'Errico \\ Politecnico di Milano \\ Daniele Farrace, Sushant S. Pandurangi, and Yuri M. Wright \\ ETH Zurich \\ Muhammad Aqib Chishty, Michele Bolla, and Evatt Hawkes \\ University of New South Wales
}

\begin{abstract}
The $4^{\text {th }}$ Workshop of the Engine Combustion Network (ECN) was held September 5-6, 2015 in Kyoto, Japan. This manuscript presents a summary of the progress in experiments and modeling among ECN contributors leading to a better understanding of soot formation under the ECN "Spray A" configuration and some parametric variants. Relevant published and unpublished work from prior ECN workshops is reviewed. Experiments measuring soot particle size and morphology, soot volume fraction $\left(f_{\mathrm{v}}\right)$, and transient soot mass have been conducted at various international institutions providing target data for improvements to computational models. Multiple modeling contributions using both the Reynolds Averaged Navier-Stokes (RANS) Equations approach and the Large-Eddy Simulation (LES) approach have been submitted. Among these, various chemical mechanisms, soot models, and turbulence-chemistry interaction (TCI) methodologies have been considered.
\end{abstract}

CITATION: Skeen, S., Manin, J., Pickett, L., Cenker, E. et al., "A Progress Review on Soot Experiments and Modeling in the Engine Combustion Network (ECN)," SAE Int. J. Engines 9(2):2016, doi:10.4271/2016-01-0734. 


\section{INTRODUCTION}

High-pressure, turbulent, compression-ignition sprays are among the most challenging research areas in combustion science encompassing numerous disciplines over a wide range of length and time scales. Topics of interest include internal nozzle flows with cavitation, multi-phase flows with liquid breakup, atomization, and vaporization in potentially trans- to super-critical regimes, turbulent mixing, gas-phase chemical kinetics, soot particle chemistry, aerosol dynamics, and radiation.

Given this broad range of disciplines, clearly it is advantageous to coordinate efforts among researchers toward a common set of conditions. Such a targeted effort will undoubtedly lead to more rapid progress in understanding the complexities of such systems and leveraging physics toward improved designs through computational fluid dynamics (CFD) models for engine sprays. With this purpose in mind, the Engine Combustion Network (ECN) was founded in 2010 as a means of coordinating collaborative experimental research efforts among international institutions to provide highly vetted targets for engine spray CFD model development and validation.

Prior experimental datasets compiled by ECN participants have been published on characterizing the various combustion vessel boundary conditions [1] , injector geometry and hydraulic behavior $[\underline{2}, \underline{3}, \underline{4}]$, and spray development, vaporization, and combustion [ $\underline{5}$ ]. The present work provides a review of the experimental and simulation contributions from ECN participants on the topic of soot in highpressure combusting spray flames.

\section{EXPERIMENTAL CONTRIBUTIONS}

High-pressure spray experiments targeting soot measurements have been conducted at Sandia National Labs (SNL, USA), IFP Energies Nouvelles (IFPEN, France), and Universitat Politecnica de Valencia (UPV, Spain). Soot collected at IFPEN was analyzed using Transmission Electron Microscopy (TEM) at Meiji University (MU, Japan). A brief description of the high-pressure combustion vessels and diagnostics used at the various institutions is provided below. The ECN "Spray A" condition (see Table 1) was the primary target of the experimental work; however, parametric variations in ambient temperature, density, and oxygen concentration were also considered. The fuel injectors belong to a family of nominally identical singlehole injectors supplied to the ECN by Bosch.

\section{Experimental Vessels}

\section{Constant Volume Vessel}

SNL and IFPEN use constant-volume, high-pressure, hightemperature spray vessels. The vessels achieve thermodynamic conditions relevant to modern compression ignition engines prior to liquid fuel injection via spark ignition of a combustible gas mixture. While the time needed for gas handling between fuel injections limits the experimental repetition rate to one injection every few minutes, the constant volume design can achieve temperature and pressure conditions exceeding the current capabilities of higher repetition rate constant pressure designs. The design and operation of the SNL and IFPEN vessels have been described in detail previously $[\underline{6}, \underline{7}, \underline{8}]$. For the experiments presented here, IFPEN and SNL used injectors \#210678 and \#210370, respectively, from the family of ECN Spray A injectors.

\section{Constant Pressure Vessel}

UPV conducted soot experiments in a constant pressure vessel, which allows for a higher experimental repetition rate, but is limited to a peak temperature of $1000 \mathrm{~K}$. Constant pressure/temperature conditions are maintained by a flow of heated and pressurized gases. Reactants and/or products from each injection are flushed from the system by the flow of fresh gases permitting repeated injections at approximately $1 \mathrm{~Hz}$. The constant pressure vessel was designed at the institute for combustion technology (ITV) of RWTH Aachen University and has been described in detail by Payri et al. [9]. Injector \#210675 from the family of ECN Spray A injectors was employed at UPV.

Table 1. ECN Spray A Condition

\begin{tabular}{|c|c|}
\hline Fuel & n-dodecane \\
\hline Injection Pressure & $150 \mathrm{MPa}(1500 \mathrm{bar})$ \\
\hline Orifice Diameter & $90 \mu \mathrm{m}($ nominal $)$ \\
\hline Ambient Temperature & $900 \mathrm{~K}$ \\
\hline Ambient Density & $22.8 \mathrm{~kg} / \mathrm{m}^{3}$ \\
\hline Ambient $\mathrm{O}_{2}$ & $15 \% \mathrm{vol}$. \\
\hline
\end{tabular}

\section{Soot Diagnostics}

\section{Planar Laser-Induced Incandescence (PLII)}

IFPEN used single-shot PLII calibrated with point-based, heliumneon $(\mathrm{HeNe})$ laser line-of-sight extinction measurements to quantify the soot volume fraction $\left(f_{\mathrm{v}}\right)$ in the central plane of high-pressure combusting sprays [10]. PLII images were acquired at different timings after the start of injection (ASOI) to assess the temporal evolution of soot formation. Several PLII images were also acquired at the same time ASOI in repeated experiments during the quasisteady period of the spray to generate an ensemble average representation of the quasi-steady $f_{\mathrm{v}}$. Parametric variations around the nominal Spray A condition in ambient temperature and oxygen concentration were considered to assess their effects and provide additional target data for engine spray combustion modeling efforts.

\section{Diffused Back-Illumination Extinction Imaging (DBIEI)}

Time-resolved images of soot optical thickness $(K L)$ in high-pressure spray flames were acquired at Sandia National Labs (SNL) and Universitat Politecnica de Valencia (UPV) using a diffused, backillumination, extinction imaging (DBIEI) diagnostic.

The optical setup consists of a high-intensity, diffused illumination source and a high-speed camera equipped with the necessary band-pass and neutral density filters. The original diffused illumination source used at SNL $[\underline{3}, \underline{11}]$ followed the design of 
Ghandi and Heim [12], and this configuration was also implemented in the DBIEI measurements presented here from UPV; however, a new optical configuration characterized by a much larger region of spatial uniformity and more diffused rays at the imaging plane has been developed at SNL as described in Westlye et al. [13]. The improved optical setup reduces perceived attenuation due to beam steering. Results from SNL using both the original and improved illumination setup are included here.

As a line-of-sight diagnostic, DBIEI maps of $K L$ must be tomographically reconstructed to obtain the dimensional extinction coefficient, $K$. The dimensional extinction coefficient can then be related to the radial distribution of $f_{\mathrm{v}}$ at the central spray plane through calculations using the Rayleigh-Debye-Gans approximation for fractal aggregates (RDG-FA) as described in Manin et al. [11].

Tomographic reconstruction of projected data from a nonaxisymmetric source can be accomplished using the inverse Radon transform. The accuracy of the reconstruction is greatest when projected data are available from multiple viewing angles. Because only a single view of the spray event is available in these DBIEI experiments, the additional projected views are generated by weighted interpolation. The uncertainty introduced into the $f_{\mathrm{v}}$ profiles because of this interpolation is an inherent weakness of the DBIEI diagnostic.

On the other hand, $K L$ is proportional to the path-integrated mass of particles in the attenuating medium. Thus, the DBIEI diagnostic can provide a more accurate measure of the total soot mass than a planar diagnostic such as PLII. A determination of total soot mass from $f_{\mathrm{v}}$ measurements by PLII requires an assumption of axisymmetry followed by integration of the revolved $f_{\mathrm{v}}$ distribution.

With a sufficiently long injection duration, the turbulent combusting sprays achieve quasi-steady behavior. By time-averaging the temporally resolved $K L$ images over the quasi-steady period and subsequently ensemble averaging data from repeated experiments, an axisymmetric map of the $K L$ field is obtained, which can be tomographically reconstructed to yield $K$, and subsequently $f_{v}$, using the inverse Radon transform mentioned above or the simpler inverse Abel transform. For the SNL experiments presented here, quasisteady soot measurements were performed with a 6-ms injection duration. Time averaging began after the spray head passed outside the field of view at approximately $2.5 \mathrm{~ms}$ and continued until just prior to the end of injection at $5.8 \mathrm{~ms}$.

Finally, Manin et al. [11] demonstrated the use of two different LED wavelengths in an alternating fashion to extract information about the optical properties of the spray flame soot. Specifically, the dispersion exponent can be derived from the ratio of extinction measured at two different wavelengths. The dispersion exponent can then be related to the carbon-to-hydrogen ratio $(\mathrm{C} / \mathrm{H})$, which provides some indication of the soot maturity. We must add that for incident wavelengths shorter than about $450 \mathrm{~nm}$, molecular absorption by large polycyclic aromatic hydrocarbons (PAH) may be a source of uncertainty in such measurements.

\section{Particle Sampling and Transmission Electron Microscope (TEM) Analysis}

Soot particles formed during high-pressure spray combustion were collected on TEM grids by IFPEN and shipped to MU for TEM analysis [14]. During sampling, the probe was positioned slightly off the main jet flow axis such that only half of the jet impinged onto the probe, while the other half of the spray was minimally disturbed. The particle-laden flow entered the probe through a 1-mm diameter hole, and soot particles were deposited onto the TEM grid. The restricted flow passage ensures flame quenching and also protects the grid against excessive heating $[\underline{15}, \underline{16}]$.

MU investigated the samples using high-resolution transmission electron microscopy (HR-TEM: JEM-2100F, operating voltage: 200 $\mathrm{keV}$, point resolution: $0.19 \mathrm{~nm}$ ). The TEM grids were interrogated without any thermal or chemical pre-treatment to avoid altering properties that may be characteristic of soot particles produced in Diesel flames. More than 25 TEM images were taken at five different locations on each TEM grid using a magnification of $20,000 \times$. The time between the sampling and the TEM investigation was slightly longer than one month; however, Aizawa et al. [1] ] reported that such a delay does not impact the measured results.

\section{MODELING CONTRIBUTIONS}

Computational Fluid Dynamic (CFD) modeling of soot formation and oxidation in high-pressure combusting sprays was performed by Argonne National Laboratory (ANL, USA), Politecnico di Milano (PM, Italy), ETH Zurich (ETHZ, Switzerland), the University of Wisconsin (UW, USA), and the University of New South Wales (UNSW, Australia). A brief description of the different approaches is provided below.

\section{$A N L$}

ANL used the commercial software "Converge" to perform simulations using a dynamic structure large-eddy simulation (LES) model. The calculations use the traditional Lagrangianparcel Eulerian-fluid approach incorporating models for spray injection, atomization and breakup, turbulence, droplet collision, and coalescence. The Favre-averaged Navier-Stokes equations in conjunction with the LES-based turbulence model describe the gas-phase flow field. The dynamic structure model was shown to most accurately capture the experimental mixture fraction relative to other sub-grid scale models [17], and the initial turbulence levels were set based on experimental measurements. The chemical kinetic model for $n$-dodecane combustion includes 105 species and 420 reactions [18], while combustion is treated with a well-mixed model. Soot was modeled using the methodology of Hiroyasu [19] with acetylene $\left(\mathrm{C}_{2} \mathrm{H}_{2}\right)$ as the soot precursor. Additional details are available in Refs. $[\underline{20}, \underline{21}, \underline{22}, \underline{23}]$.

\section{Politecnico di Milano, Italy (PM)}

PM used the opensource CFD platform OpenFOAM ${ }^{\circledR}$, together with a set of internally developed solvers and libraries referred to as Lib-ICE [24]. The gas phase is described by the unsteady Reynoldsaveraged Navier-Stokes (URANS) formulation. The mass, 
momentum, and energy equations are solved for a compressible, multi-component flow using the second-order, unstructured finitevolume method supporting polyhedral cells. The standard $\mathrm{k}-\varepsilon$ model was used for turbulence. In order to match the experimental vapor penetration, the constant $C_{\varepsilon 1}$ was changed from 1.44 to 1.55 . This practice is quite common in simulation of gas jets and is referred to as the "round jet correction". Assigning a value of 1.55 to $C_{\varepsilon 1}$ ensures a very good matching between computed and experimental vapor penetration data in a wide range of operating conditions. Concerning initial turbulence data, turbulence intensity and the integral length were set to $0.25 \mathrm{~m} / \mathrm{s}$ and $1 \mathrm{~mm}$, respectively. Such data are considered representative of constant volume vessel conditions after the pre-burn event. Pressure and velocity equations are coupled by the pressureimplicit method for pressure-linked equations (PIMPLE) algorithm. The discrete droplet method (DDM) is used to compute the evolution of the liquid fuel spray. Jet and droplet breakup are computed by the KHRT model, which accounts for both Kelvin-Helmholtz $(\mathrm{KH})$ and Rayleigh-Taylor (RT) instabilities. The turbulence-chemistry interaction is modeled with the multiple representative interactive flamelet (mRIF) model, using a skeletal mechanism with 54 species and 269 reactions [ $\underline{25}$ ] for the $n$-dodane chemistry. Soot inception, coagulation, surface growth and oxidation are described as in Moss et al. [26] with acetylene $\left(\mathrm{C}_{2} \mathrm{H}_{2}\right)$ as the main precursor.

\section{ETH Zurich, Switzerland (ETHZ)}

ETHZ used the commercial CFD software STAR-CD v4.22 coupled with an in-house combustion code. A RANS approach was employed with the standard $k-\varepsilon$ model. A round-jet correction was applied to this model by modifying the constant $C_{\varepsilon 1}$ to 1.52 to capture the penetration length as closely as possible. Initial conditions for turbulence were based on a turbulent fluctuation and length scale of 1 $\mathrm{m} / \mathrm{s}$ and $0.1 \mathrm{~mm}$ respectively, representative of near-quiescent conditions before injection. To incorporate the liquid-phase fuel spray, a Lagrangian approach was used with the blob model for atomization and the Reitz-Diwakar [27] model for droplet secondary breakup. Turbulence-chemistry interaction was accounted for by the conditional moment closure (CMC) approach, previously applied for simulation of various high-pressure spray test rigs $[\underline{28}, \underline{29}, \underline{30}, \underline{31}, \underline{32}]$.

For soot modeling, the semi-empirical two-equation model of Leung et al. [33] was employed within the $\mathrm{CMC}$ framework. The model considers inception (from $\mathrm{C}_{2} \mathrm{H}_{2}$ ), surface growth, oxidation (by $\mathrm{O}_{2}$ and $\mathrm{OH}$ ) and coagulation. For Spray A, the simplified n-dodecane mechanism from Luo et al. [18] was applied using in-situ adaptive tabulation (ISAT) [푸] to reduce computational effort. An extended CMC model was employed to account for multiple injections [31].

\section{University of Wisconsin, USA (UW)}

UW used the open source code KIVA3V release 2 [35] to provide the CFD platform for the simulations. The generalized RNG k- $\varepsilon$ turbulence model proposed by Wang and Reitz [36] was applied to improve the prediction of fuel mixture distribution under nonreacting condition. The spray breakup process was predicted by the $\mathrm{KH}-\mathrm{RT}$ instability model $[\underline{37}, \underline{38}]$. A reduced $n$-dodecane-PAH mechanism with 100 species and 432 reactions was used to predict the $n$-dodecane combustion and PAH formation processes [39] using a well-mixed model. The multi-step soot model developed by Vishwanathan and Reitz [으] was applied to predict the soot formation and oxidation processes. In this modeling approach, soot particle inception occurs with the formation of pyrene $\left(\mathrm{C}_{16} \mathrm{H}_{10}\right)$, then the soot particle undergoes the $\mathrm{C}_{2} \mathrm{H}_{2}$ assisted surface growth, coagulation, and soot is oxidized by $\mathrm{O}_{2}$ and $\mathrm{OH}$ radicals and $\mathrm{PAH}$ condensation on the soot particle surface. More details about this modeling approach can be found in $[\underline{40}, \underline{41}]$.

\section{University of New South Wales, Australia (UNSW)}

UNSW employed the commercial software "Fluent" to perform simulations using the transported probability density function (tPDF) method [42] with the interaction by exchange with the mean (IEM) mixing model. The unsteady RANS equations coupled with the realizable $\mathrm{k}-\varepsilon$ turbulence model were used to provide turbulence information to the tPDF solver. The $C_{\mathrm{e} 1}$ constant from the turbulence model has been augmented from 1.44 to 1.52 to match the experimental vapor penetration. The field has been initialized as quiescent with a turbulent velocity and integral length scale of 0.1 $\mathrm{m} / \mathrm{s}$ and $2 \mathrm{~mm}$, respectively. These initial values were found to have a minor influence on the spray development. A reduced ndodecane chemical mechanism including 54 species and 269 reactions [25] was used. The soot formation model is identical to that of ETHZ using an acetylene-based two-equation model [ [33] , which accounts for simultaneous soot particle inception, surface growth, coagulation and oxidation by $\mathrm{O}_{2}$ and $\mathrm{OH}$. Additional details are available in $[\underline{43}, \underline{44}]$. For selected test cases, simulations have also been performed with the well-mixed model for chemical reaction rates - neglecting turbulent fluctuations - to directly study the influence of TCI.

\section{RESULTS AND DISCUSSION}

To support the purposes of the ECN, the present work reports on experimental and modeling results that have been prepared for prior ECN workshops. New results not yet available in the literature are presented and discussed along with those previously published.

The results presented below are organized as follows. First, recognizing the strong coupling between mixing and ignition processes with soot formation, we present a comparison of experimental and simulated vapor penetration, ignition delay times, and lift-off length. As a necessary prerequisite for optical soot measurements, we then present TEM results relating to soot morphology and the determination of parameters required to relate extinction measurements to soot volume fraction. Of particular importance is the finding that the primary particle diameter of soot particles formed in high pressure spray flames is significantly smaller than those observed in atmospheric pressure flames. Following the discussion of the TEM data, we present experimental and modeling results for the early soot formation transients. Quasi-steady soot results are then presented for Spray A and a few parametric variants. Lastly, we present experimental and modeled results for transient soot formation at the Spray A condition with multiple injections. 


\section{Penetration, Ignition Delay, and Lift-off Length for Model Validation}

There is significant utility in time-resolved measurements of transient processes in high-pressure combusting sprays as validation targets for CFD models. For example, before trusting any comparison of modeled soot results to experiments, the models should demonstrate that they can accurately capture the experimentally determined vapor penetration and ignition delay time. For long injection duration cases, a quasi-steady lift-off length is also established providing yet another relevant model validation target. This section briefly compares the simulated vapor penetration, ignition delay time, and quasi-steady lift-off length against experimental data available from the ECN community.

\section{Vapor Penetration}

Pickett and coworkers [45] highlighted the strong relationship between spray development and global mixing. As such, jet penetration can be used as a metric to evaluate the mixing fields across modeling predictions and compare them to the experimental results. The experimental vapor penetration under the non-reacting Spray A condition is presented in Fig. 1 along with the simulated results. The experimental curve (solid black) represents the average of several injections carried out with nozzle \#210370 at SNL and nozzle \#210675 at CMT. These two Spray A nozzles have similar orifice diameters and discharge $\left(C_{\mathrm{d}}\right)$ and area contraction $\left(C_{\mathrm{a}}\right)$ coefficients and were the targets of the modeling efforts presented in this work. The standard deviation of these two datasets is too small to be resolved on this figure; however, for reference, the grey shaded region represents the standard deviation from the mean of all non-reacting Spray A vapor penetration data available on the ECN data archive. This includes data from five different institutions using five different nozzles. It is noted that the average penetration of \#210370 and \#210675 falls on the upper bound of the grey shaded region, which is consistent with the slightly larger orifice diameters of \#210370 and \#210675 relative to the other Spray A nozzles.

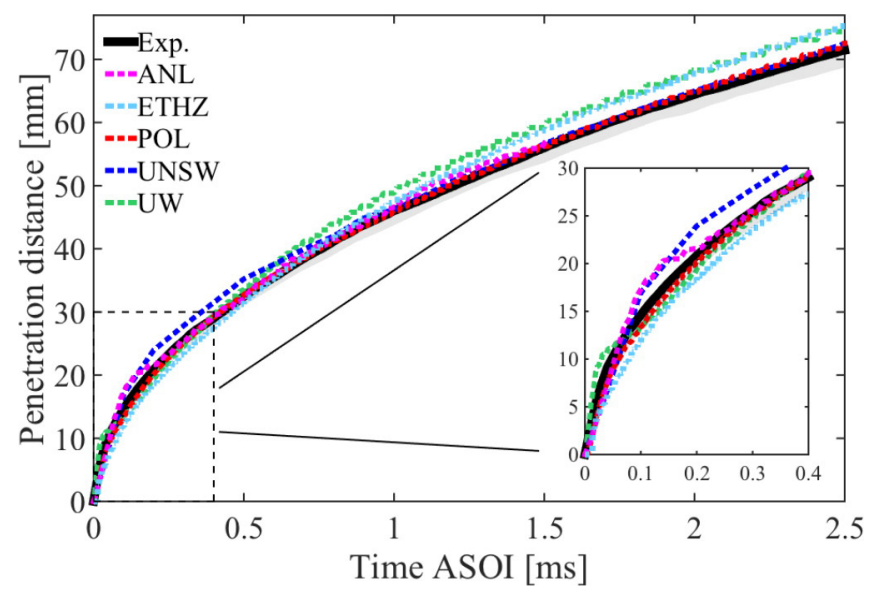

Figure 1. Experimental and modeled non-reacting vapor penetration of an $\mathrm{n}$-dodecane spray issuing from a $90-\mu \mathrm{m}$ (nominal) orifice at $1500 \mathrm{bar}(150$ $\mathrm{MPa}$ ). Ambient conditions: $900 \mathrm{~K}, 22.8 \mathrm{~kg} / \mathrm{m}^{3}, 0 \% \mathrm{O}_{2}$.

At timings prior to ignition for the reacting Spray A case (i.e., $<0.4$ ms ASOI) the ETH and POL models most accurately reproduce the experimental penetration data (see Fig. 1 inset), with the UW and
ANL models initially penetrating too quickly before relaxing to the experimental data at $0.05 \mathrm{~ms}$ and $0.2 \mathrm{~ms}$, respectively. With the exception of the UW result, which shows greater penetration than the experiment after approximately $0.5 \mathrm{~ms}$, the models all appear to reproduce the experimental non-reacting vapor penetration at later times relevant to soot formation at the Spray A condition. We note, however, that the ETHZ vapor penetration diverges slightly from the experimental data near $1.1 \mathrm{~ms}$, which is after soot formation begins at the Spray A condition.

\section{Ignition Delay}

Four institutions participating in the ECN have measured experimental ignition delay times at the Spray A baseline condition. For the parametric variants in temperature at $750 \mathrm{~K}, 800 \mathrm{~K}$, and 850 $\mathrm{K}$, two institutions have contributed data. At $1000 \mathrm{~K}$ and above, only SNL has contributed ignition delay data. The experimental and simulated ignition delay times as a function of ambient temperature at an ambient density of $22.8 \mathrm{~kg} / \mathrm{m}^{3}$ and an ambient oxygen concentration of $15 \%$ are presented in Fig. 2. The standard error is included for datasets combined across institutions where applicable. At ambient temperatures of $1000 \mathrm{~K}$ and above, ignition delay times are highly repeatable and the standard error cannot be resolved in the figure. The ignition delay values at the Spray A condition are also tabulated in the figure for reference and the experimental value includes the standard error. Note that the ANL ignition delay time at $900 \mathrm{~K}$ is the average of five LES realizations and the standard error from these simulations is included in the table as well. Pei et al. [23] provides more detail regarding the variation among different LES realizations.

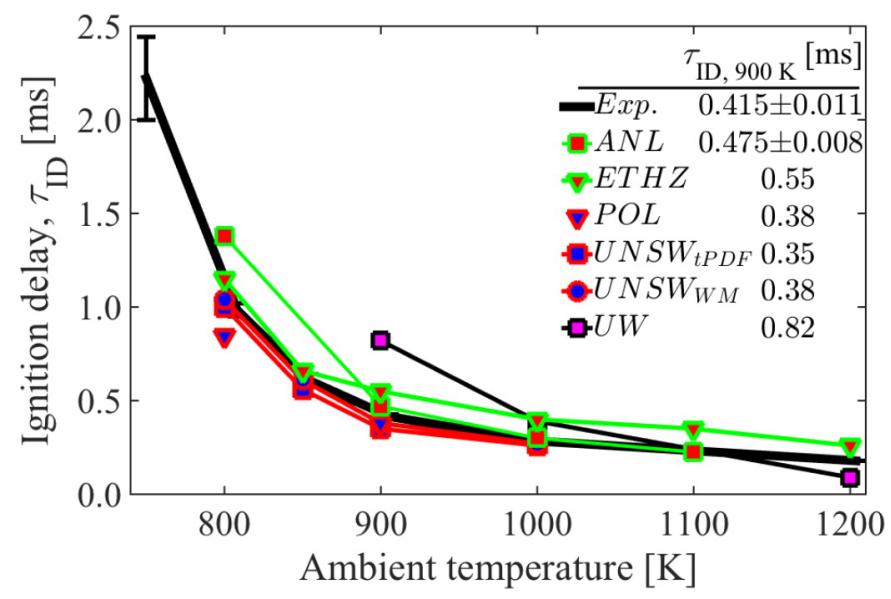

Figure 2. Experimental and simulated ignition delay times for Spray A and its parametric variants in ambient temperature.

The ANL, UNSW, and POL simulations best reproduce the experimental trends and quantities for ignition delay, with only a slight difference between the tPDF and well-mixed models of UNSW; however, it should be noted that the chemical mechanism implemented in the POL and UNSW simulations was specifically tuned by Yao et al. [25] to ECN spray combustion data. A consistent over-prediction of ignition delays is seen for the ETHZ results at 900 $\mathrm{K}$ and above using the Luo et al. 106-species chemistry. This systematic over-prediction was also found in perfectly-stirred reactor (constant-volume) simulations compared to shock tube data. The UW 
ignition delay is around twice as long as the experimental value at the Spray A condition, which complicates the comparison of timeresolved soot results later.

\section{Lift-off Length}

Five institutions participating in the ECN have measured the quasi-steady lift-off length at the Spray A baseline condition, with two institutions contributing data at lower ambient temperature and only SNL providing measurements at $1000 \mathrm{~K}$ and above. Figure 3 displays the experimental and simulated quasi-steady lift-off lengths as a function of ambient temperature under the same conditions as Fig. 2. For the ambient temperature conditions at $900 \mathrm{~K}$ and below, the standard error among the different contributing institutions is provided. For $1000 \mathrm{~K}$ and above, the standard error is derived from two independent SNL experimental campaigns. The liftoff length results for the Spray A baseline case are also tabulated in the figure for reference. The ANL result at $900 \mathrm{~K}$ is the average of $15 \mathrm{LES}$ realizations, while for the other ambient temperatures only a single realization was performed. The tabulated ANL result for Spray A also includes the standard error.

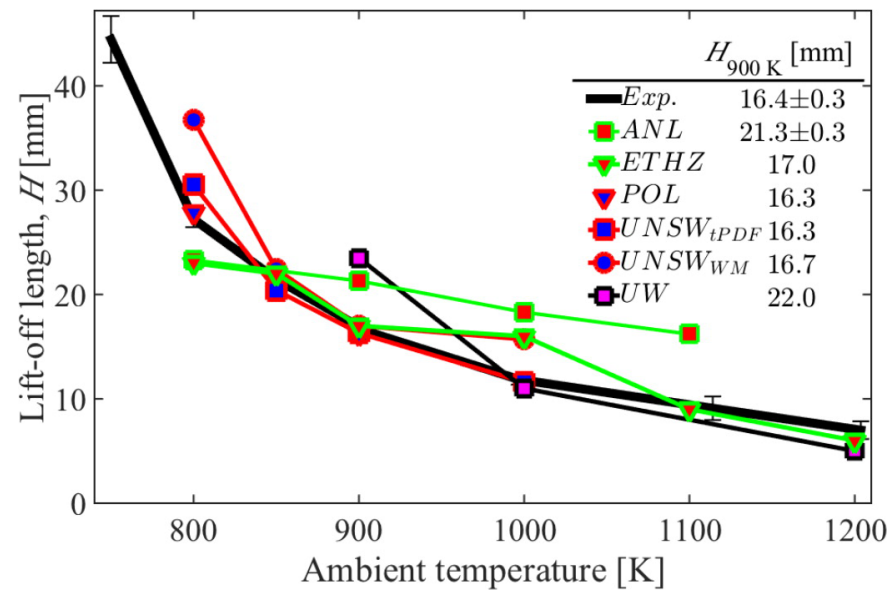

Figure 3. Experimental and simulated quasi-steady lift-off lengths $(\mathrm{H})$ for Spray A and its parametric variants in ambient temperature.

In comparing the simulated lift-off lengths with the experimental results, we observe good agreement from the POL and UNSW tPDF models, while the UNSW well-mixed model diverges from the experiment at $800 \mathrm{~K}$ and $1000 \mathrm{~K}$. The ETHZ lift-off length also diverges at these two temperatures; however, in contrast to the UNSW well-mixed model, the lift-off length at $800 \mathrm{~K}$ is instead under-predicted by ETHZ. The ANL lift-off length trend is nearly linear, with a shorter lift-off length than the experiment at $800 \mathrm{~K}$ and a longer value at $900 \mathrm{~K}$ and above; however, this might be due to the insufficient number of LES realizations for temperatures other than the Spray A case. Although the standard error of the lift-off length for the 15 LES realizations is quite small, fluctuations in lift-off length extend down to $17 \mathrm{~mm}$ and up to $24 \mathrm{~mm}$ during the transient simulation [를. More realizations are necessary to build up sufficient statistics for a representative trend at this and other conditions; however, the high computational cost of these simulations is prohibitive. Finally, it is interesting to note that the UNSW wellmixed model matches ETHZ at $900 \mathrm{~K}$ and $1000 \mathrm{~K}$ even though different mechanisms were used. Clearly, a more in-depth analysis of the modeling parameters influencing ignition delay and lift-off length among the various models is warranted and should be the subject of future $\mathrm{ECN}$ work.

\section{Soot Optical Properties and TEM Imaging for Soot Morphology}

Knowledge of the in-situ soot optical properties and morphology is necessary to reduce uncertainty when making optical measurements of soot volume fraction $\left(f_{\mathrm{v}}\right)$ in flames. For LII measurements calibrated by laser extinction or extinction imaging measurements as will be presented below, the dimensionless extinction coefficient $\left(k_{\mathrm{e}}\right)$ is a critical parameter in relating the measured optical attenuation $\left(I / I_{0}\right)$ to $f_{\mathrm{v}}$ through Bouguer's Law. Because $k_{\mathrm{e}}$ is not only dependent on particle refractive index, but also morphology, care must be taken to account for the effect of soot particle aggregation on the scatteringto-absorption ratio $\left(\alpha_{\mathrm{sa}}\right)$. Provided the appropriate particle and aggregate parameters can be determined, the influence of aggregation can be captured by the Rayleigh-Debye-Gans approximation for fractal aggregates (RDG-FA). The information on particle size and morphology necessary to derive $k_{\mathrm{e}}$ via RDG-FA calculations includes the complex refractive index $(m)$, primary particle diameter $\left(d_{\mathrm{p}}\right)$, fractal prefactor $\left(k_{\mathrm{f}}\right)$, fractal dimension $\left(D_{\mathrm{f}}\right)$, and aggregate size $\left(N_{\mathrm{p}}\right)$. This section provides a brief explanation of the soot refractive index selected for use by the ECN along with a review of TEM imaging results from ECN participants and others providing the necessary information to determine $k_{\mathrm{e}}$ in high-pressure spray flames.

Numerous studies have investigated the refractive index of flameformed soot as well as other types of carbonaceous particles as reviewed by Smyth and Shaddix [ㄷ] and Bond and Bergstrom [느]. While the refractive index applied for extinction measurements can be dependent on a variety of parameters including the wavelength of the incident light and soot composition (i.e., carbon-to-hydrogen ratio), the ECN community has adopted the refractive index proposed by Williams et al. [48] of 1.75-1.03i. Although Williams et al. indicated that this refractive index was specific to measurements at $635 \mathrm{~nm}$, we apply this value as the standard across measurements in the visible spectrum to simplify the comparison of ECN soot measurements performed by different institutions and with different incident wavelengths. The consequences of choosing a constant refractive index for the analysis of soot in spray flames is discussed later in the context of the $k_{\mathrm{e}}$ derived from RDG-FA calcualtions. More information on this subject can be found in Manin et al. [11].

With regard to primary particle size, TEM analysis published in Cenker et al. [14] showed a count median diameter of $9.1 \mathrm{~nm}$ for soot sampled 60-mm from the injector orifice under the Spray A condition. While this was the only spatial location sampled for Spray A, TEM analysis was also performed on samples extracted at three axial locations, namely, $36 \mathrm{~mm}, 45 \mathrm{~mm}$, and $60 \mathrm{~mm}$ from the $21 \% \mathrm{O}_{2}$ parametric variant of Spray A. Although the higher ambient oxygen concentration is known to impact the soot onset timing as well as the rate and location of soot burnout, these data provide relevant insight into the axial evolution of particle morphology. Representative TEM images from the soot formation and oxidation regions as well as the particle-size histograms from soot sampled at all three locations are shown in Fig. 4. For this condition, the 36-mm location is slightly 
downstream of the soot onset region during quasi-steady burning of the spray flame and is characterized by a median count diameter of $14.7 \mathrm{~nm}$. At the 45-mm location, which is near the center of the soot region axially and represents the location of peak $f_{\mathrm{v}}$, a median count diameter of $9.9 \mathrm{~nm}$ was observed. The $60-\mathrm{mm}$ location is near the region of soot burnout with a median count diameter of $7.3 \mathrm{~nm}$.

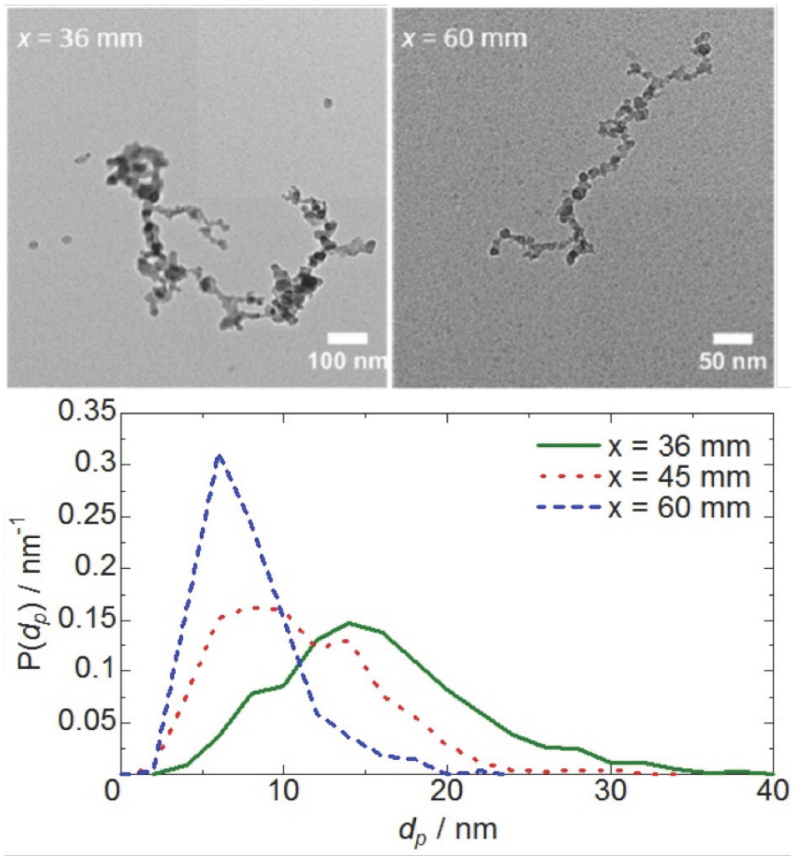

Figure 4. Upper panel: TEM micrographs of soot sampled from an n-dodecane spray flame at the Spray A $1000 \mathrm{~K}$ temperature variant condition. Lower panel: Primary particle size distribution determined by TEM analysis.

Kook and Pickett [15], Aizawa et al. [16], and Nishigai et al. [뚜] also observed mean primary particle diameters smaller than $20 \mathrm{~nm}$ in high-pressure diesel spray flames. Kook and Pickett [15] sampled soot particles from a surrogate jet fuel consisting of $23 \% \mathrm{~m}$-xylene and $77 \%$ n-dodecane (by volume) and a conventional jet fuel composed of an equal blend of five Jet-A samples from different US manufacturers. At the location of peak $f_{\mathrm{v}}$, the m-xylene/n-dodecane flame was characterized by a count mean primary particle diameter of $16 \mathrm{~nm}$ while the Jet-A blend flame was characterized by a count mean primary particle diameter of $13 \mathrm{~nm}$. Aizawa et al. [16] performed TEM analysis on particles sampled at the location of peak $f_{\mathrm{v}}$ from combusting sprays of US \#2 Diesel and a soy-derived biodiesel consisting of five methyl-esters. The arithmetic mean primary particle diameters were $18.4 \mathrm{~nm}$ and $16.9 \mathrm{~nm}$ for the US \#2 Diesel and biodiesel fuels, respectively. Nishigai et al. [49] sampled particles at several axial locations in spray flames of a conventional diesel fuel (JIS\#2) and Fischer-Tropsch diesel (FTD). Mean primary particle diameters ranging from $12 \mathrm{~nm}$ to $20 \mathrm{~nm}$ were observed for JIS\#2, while the particles formed in FTD ranged from $11 \mathrm{~nm}$ to $14 \mathrm{~nm}$.

Though not associated with ECN efforts, it is worth noting that $\mathrm{Li}$ et al. [무] collected the contents of a diesel engine cylinder for offline analysis and observed mean primary particle diameters of approximately $22 \mathrm{~nm}$ for samples collected shortly after top dead center (TDC), rising to $29 \mathrm{~nm}$ at later timings, and decreasing to 18 $\mathrm{nm}$ at the latest sampling time. No assessment of primary particle size as a function of location within the spray flame can be made from these data because the entire cylinder volume was sampled; however, if we consider the samples extracted shortly after TDC as representative of the early formation stage and those extracted at the latest timing after TDC as representative of the oxidation stage, these results are consistent with the findings of Cenker et al. [14] described above.

Nishigai [49] also observed a non-monotonic trend in primary particle diameter as a function of axial distance from the injector, with particle diameter initially increasing and then decreasing at greater distances from the injector; however, the particles sampled in the burnout region were characterized by primary particle diameters similar to those in the formation region. Finally, Kholghy et al. [51] observed larger primary particle diameters in the formation region relative to the oxidation region in atmospheric pressure, laminar diffusion flames of a Jet A-1 surrogate fuel.

Recognizing that the soot morphological properties influencing $k_{\mathrm{e}}$ are dependent on several parameters including fuel type, ambient pressure, temperature, and oxygen concentration, as well as location within the flame, a single set of reference input parameters for computing $k_{\mathrm{e}}$ from RDG-FA was desired for consistency and to simplify comparisons of ECN soot experiments. These input parameters were determined by TEM analysis of the soot samples extracted from the surrogate jet fuel results of Kook and Pickett [52]. Values for $d_{\mathrm{p}}$ and $N_{\mathrm{p}}$ were extracted along with parameters describing the aggregate distribution such as $D_{\mathrm{f}}$ and $k_{\mathrm{f}}$.

The primary particle diameter of $16 \mathrm{~nm}$ mentioned above for the surrogate jet fuel comes from a simple arithmetic mean of the distribution presented by Kook and Pickett [52]. The values for $N_{\mathrm{p}}$ along with $k_{\mathrm{f}}$ and $D_{\mathrm{f}}$ have been determined from those data by considering over one thousand aggregates, ranging from 3 to approximately 400 particles. The upper bound was limited to include $99 \%$ of the aggregates because of unrealistically large aggregates found in the upper $1 \%$. An arithmetic mean was also used to obtain an equivalent mean aggregate size and this value was rounded, for convenience, to yield a value of $N_{\mathrm{p}}=150$. As explained by Manin et al. [11], an arithmetic mean might not be the most appropriate way to describe the aggregate distribution, but this method tends to provide angular scattering patterns equivalent to the polydisperse simulations in the Guinier regime. The Guinier part of the angular scattering function describes the light scattered by the aggregates at small angles (as opposed to the power-law for the larger angles), mainly responsible for the extinction measured by the DBIEI diagnostic. The values of $D_{\mathrm{f}}$ and $k_{\mathrm{f}}$ were determined to be 1.77 and 8.36, respectively, by fitting the TEM-extracted distribution using a method similar to that proposed by Köylü et al. [푸] .

Having the necessary parameters available, Manin et al. [11] computed $k_{\mathrm{e}}$ via RDG-FA for incident wavelengths of $406 \mathrm{~nm}$ and $519 \mathrm{~nm}$ to be 7.76 and 7.46, respectively. As the LII measurements of IFPEN were calibrated based on HeNe laser extinction and recent DBIEI measurements from SNL are presented here using $632 \mathrm{~nm}$ incident light, a $k_{\mathrm{e}}$ value at this wavelength was computed to be 7.29. Soot volume fraction quantities published by Cenker et al. [1ㅇ] were 
determined using the $k_{\mathrm{e}}$ value previously recommended by the ECN of 8.7; however, the data reproduced from Cenker et al. in the present work have been adjusted to account for the updated $k_{\mathrm{e}}$.

\section{Spray A: Early Soot Transients}

The temporal evolution of the soot volume fraction $\left(f_{\mathrm{v}}\right)$ in parts-permillion (ppm) for Spray A (1.5-ms injection duration) at the central plane of the spray axis as measured by LII at IFPEN is displayed in the top row of Fig. 5. These are ensemble-average soot maps for four injection events at nominally identical conditions and the $f_{\mathrm{v}}$ values have been adjusted from those previously published by Cenker et al. [10] to account for an updated value of $k_{\mathrm{e}}$ as discussed above. The values in the upper left corner of the image represent the maximum $f_{\mathrm{v}}$ observed at the specified timing, while the bracketed values in the lower left corner of each image panel represent the upper limit of the displayed color palette. The color scale corresponding to the minimum and maximum values is displayed in the lower right corner of the figure.

The second row of images in Fig. 5 displays the temporal evolution of the path integrated soot optical thickness $(K L)$ as measured by DBIEI at SNL. The values in the upper left corner of the $K L$ images designate the maximum $f_{\mathrm{v}}$ computed after tomographic inversion of the $K L$ map. For these images, the upper limit of the displayed color palette was held constant at 0.8 as indicated in the lower left corner of the images. The dashed vertical lines in the experimental LII and DBIEI data designate the locations selected for comparison of $f_{\mathrm{v}}$ from the IFPEN LII data with that determined after tomographic reconstruction of the SNL extinction data. The locations for comparison represent the cross-section with the highest $f_{\mathrm{v}}$ between 5-7 $\mathrm{mm}$ upstream of the penetration distance.

It is worth noting that both the extinction measurements at IFPEN used to calibrate the LII signal and the tomographically inverted DBIEI measurements at SNL yielding $f_{\mathrm{v}}$ have assumed constant soot morphology and thus constant $k_{\mathrm{e}}$ throughout the flame. This is in spite of the TEM measurements presented above indicating that both $d_{\mathrm{p}}$ and $N_{\mathrm{p}}$ change as a function of axial position. To quantify the potential error introduced in these assumptions, we note that for the range of $d_{\mathrm{p}}$ measured by Kook and Pickett [15], Aizawa et al. [16], and Cenker et al. [14] in combusting spray flames (7.3 nm-18.4 nm) the influence of changing $d_{\mathrm{p}}$ on $k_{\mathrm{e}}$ is approximately $4 \%$. Further, for the apparently small primary particle diameters associated with these flames, $k_{\mathrm{e}}$ changes by around $3 \%$ when varying $N_{\mathrm{p}}$ from 5 to 150 . While these uncertainties are not insignificant, they are small relative to the remaining uncertainty in soot refractive index. For example, using the refractive index of Dalzell and Sarofim [ $\underline{54}$ ] of 1.57-0.56i as opposed to that of Williams et al. [뇨] produces a $30 \%$ change in $k_{\mathrm{e}}$.

Before making a detailed comparison of the soot transients from the two experimental campaigns, some discussion of the achieved boundary conditions relative to the target conditions is warranted. As mentioned in Cenker et al. [10], the ambient temperature and density of these Spray A experiments were $930 \mathrm{~K} \pm 5 \mathrm{~K}$ and $21.8 \mathrm{~kg} / \mathrm{m}^{3} \pm 0.1$ $\mathrm{kg} / \mathrm{m}^{3}$ respectively, as opposed to the Spray A standard of $900 \mathrm{~K}$ and $22.8 \mathrm{~kg} / \mathrm{m}^{3}$. The mean ambient temperature for the five SNL Spray A injections shown in Fig. 5 was $900 \mathrm{~K} \pm 1.3 \mathrm{~K}$ with a mean ambient density of $22.0 \mathrm{~kg} / \mathrm{m}^{3} \pm 0.1 \mathrm{~kg} / \mathrm{m}^{3}$. The difference in ambient density between the IFPEN and SNL experiments is negligible; however, a $30 \mathrm{~K}$ difference in ambient temperature might have a non-trivial effect on ignition delay and lift-off length if all other parameters are equal. As shown in Figs. 2 and $\underline{3}$, ignition delay and lift-off length both decrease with increasing ambient temperature. Coupled together, shorter ignition delay times and shorter lift-off lengths can lead to increased soot formation due to combustion occurring in more fuel rich regions. When combustion occurs later or farther away from the injector tip, additional mixing occurs which results in less fuel-rich conditions and therefore less soot formation [55].

The mean ignition delay for the IFPEN Spray A cases shown in Fig. 5 was $0.4 \mathrm{~ms}$ with a mean lift-off length of $14.5 \mathrm{~mm} \pm 0.5 \mathrm{~mm}$. The five SNL Spray A cases in Fig. 5 were characterized by a mean ignition delay of $0.41 \mathrm{~ms} \pm 0.01 \mathrm{~ms}$ and a lift-off length of $16.9 \mathrm{~mm} \pm$ 0.17 . The similar ignition delay times but shorter lift-off length for the IFPEN data may be attributed to different injector flow characteristics as well as variability in the injection pressure of the IFPEN experiments.

Considering the spray head penetration, which can be observed in Fig. 5, it is clear that the SNL spray penetrates faster than that of IFPEN. For example, at $1.5 \mathrm{~ms}$ ASOI the IFPEN jet has penetrated approximately $50 \mathrm{~mm}$ while the SNL data shows a penetration distance of nearly $55 \mathrm{~mm}$. At $1.8 \mathrm{~ms}$ ASOI the difference increases to $7 \mathrm{~mm}$. Faster penetration would result from the SNL injector having a slightly larger orifice diameter and/or a higher mean injection pressure. Unfortunately, the mean injection pressure for the IFPEN runs was not recorded; however, the mean injection pressure of the SNL runs was $155 \mathrm{MPa} \pm 3 \mathrm{MPa}$, which is $5 \mathrm{MPa}$ greater than the Spray A target. With regard to injector flow characteristics, Malbec et al. [56] characterized a set of ECN Spray A injectors, including \#210678, shortly after the soot experiments at IFPEN. Compared to injector \#210675, which has been shown to have similar flow characteristics to injector \#210370, injector \#210678 used at IFPEN had a $20 \%$ lower mass flow rate at the Spray A condition (i.e., 150 $\mathrm{MPa}$ injection pressure and $6 \mathrm{MPa}$ back pressure). Such mass flow differences could explain the measured discrepancies in global penetration between IFPEN and SNL.

Indeed, the faster penetration and longer lift-off length of the SNL data suggest a larger fuel flow rate from injector \#210370, which would increase soot. Recall, however, that the IFPEN Spray A experiments were conducted at an ambient temperature of $930 \mathrm{~K}$ rather than the targeted $900 \mathrm{~K}$. The combination of the higher ambient temperature and higher equivalence ratio at the lift-off location appears to compensate for potential differences in soot formation due to higher injector flow. Thus, the peak $f_{\mathrm{v}}$ measured by IFPEN and SNL at the different timings indicated in Fig. 5 are relatively similar. To more fully explore this result, radial cross sections of $f_{\mathrm{v}}$ on a plane crossing the injector axis at select axial locations are compared in Fig. 6. The extinction maps from SNL (Fig. 5) have been inverted to extract $f_{\mathrm{v}}$. For the timings up to $1.8 \mathrm{~ms}$ ASOI, the vertical dashed vertical lines in Fig. 5 denote the locations of interest 5-7 mm upstream of the spray head. Similar $f_{\mathrm{v}}$ cross sections at later timings, namely $2.1 \mathrm{~ms}$ and $2.4 \mathrm{~ms}$, are presented in Fig. 6 as well. 

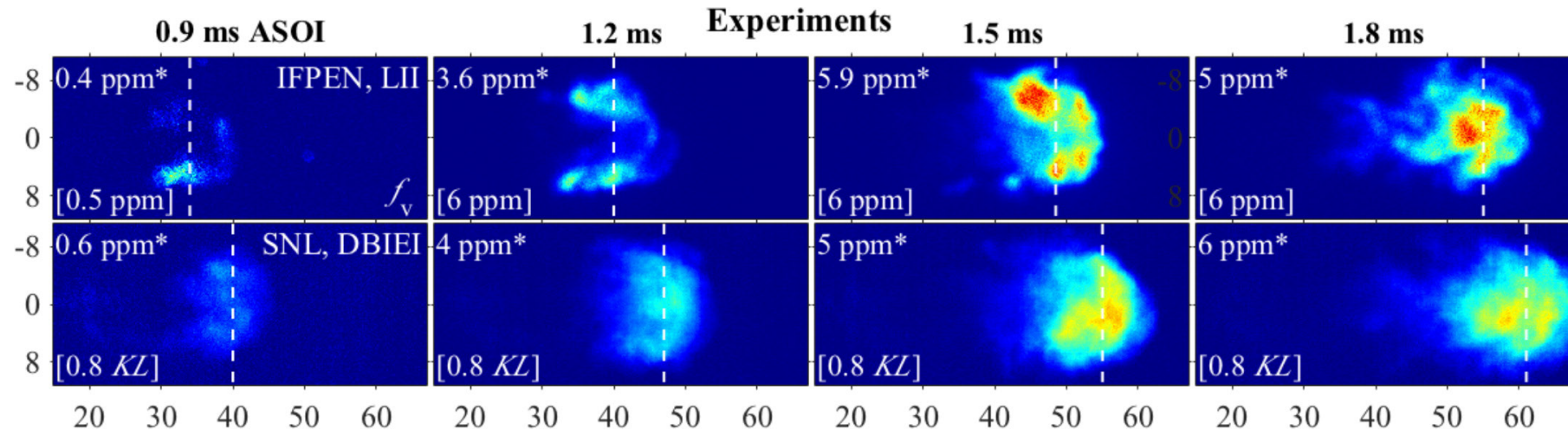

$0.9 \mathrm{~ms}$ ASOI

\section{$1.2 \mathrm{~ms}$ Simulations}
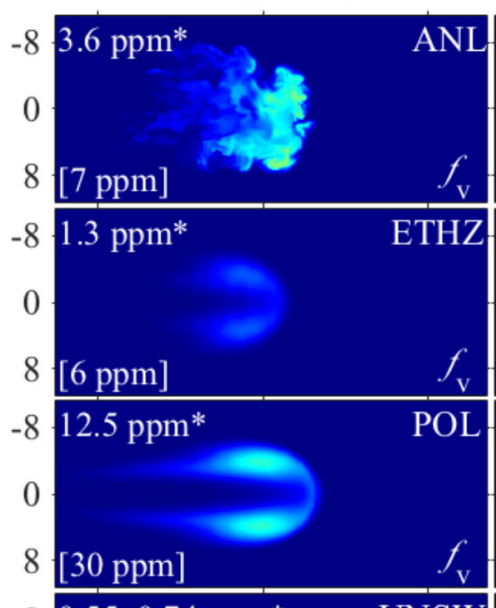

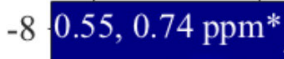

0

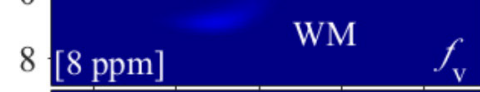

8 [6 ppm]

0

$-8$ $1 \mathrm{ppm}^{*}$

$\begin{array}{lllll}20 & 30 & 40 & 50 & 60\end{array}$
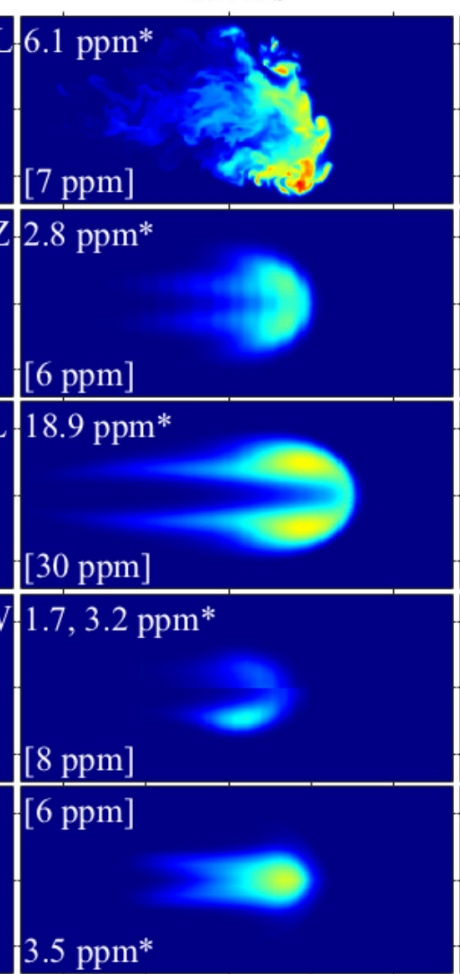

$1.8 \mathrm{~ms}$

$[30 \mathrm{ppm}]$
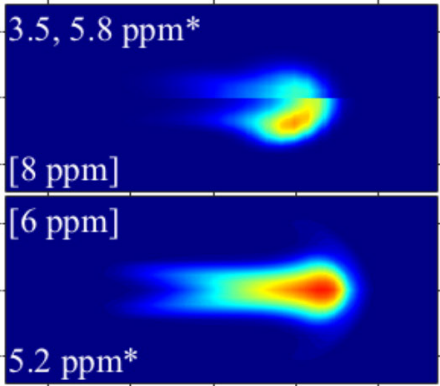

$\begin{array}{llllllllll}20 & 30 & 40 & 50 & 60 & 20 & 30 & 40 & 50 & 60\end{array}$
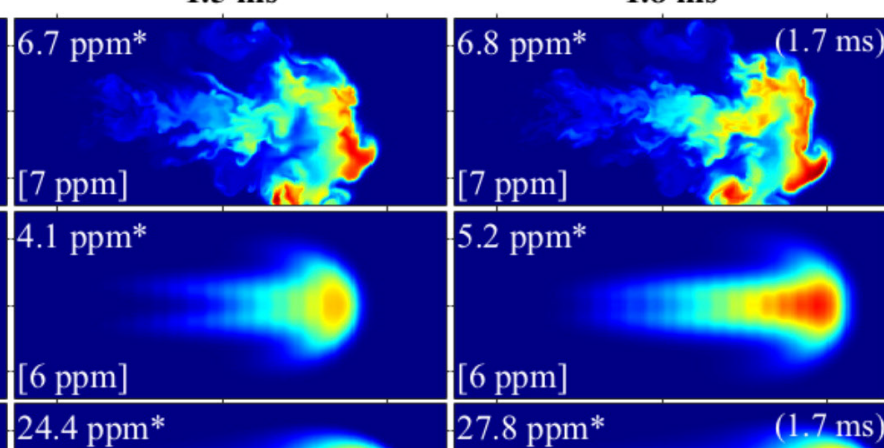

$5.2 \mathrm{ppm}^{*}$

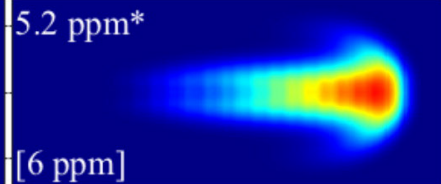

$27.8 \mathrm{ppm}^{*} \quad(1.7 \mathrm{~ms}$

Distance from injector [mm]

$\min$

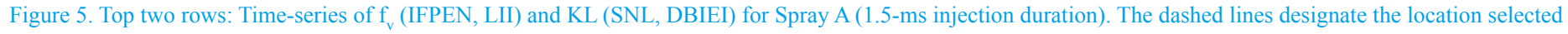

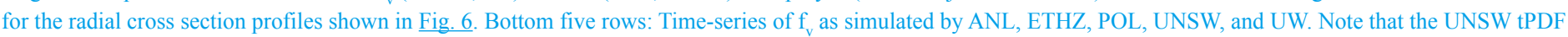
and WM results are presented in a single image.

With the exception of the earliest timing shown in Fig. 6, the experimental radial cross sections of $f_{\mathrm{v}}$ from IFPEN and SNL are remarkably similar both in shape and in amplitude. This is in spite of the requirement, discussed above, that the projected $K L$ data be interpolated for multiple viewing angles before tomographic reconstruction. The larger $f_{\mathrm{v}}$ measured by DBIEI at $0.9 \mathrm{~ms}$ may be an indication that this diagnostic is more sensitive to small quantities of soot because the attenuation is path-integrated. Nevertheless, further work should be performed in a single combustion vessel for confirmation.

As a second means of vetting the IFPEN and SNL Spray A soot datasets, a comparison of the total soot mass measured by the two diagnostics as a function of time is presented in the top panel of
Fig. 7. For reference, we have included SNL data acquired in 2012 with the original DBIEI setup using 406-nm and 519-nm incident light. Recall that the IFPEN data were acquired as a single shot at a specific instant in time for several repeated injection events, while the DBIEI data were acquired at $30-45 \mathrm{kHz}$ using high-speed imaging. With the exception of the soot mass determined from the measurements with 406-nm incident light, the IFPEN and SNL data again show reasonably good agreement. The larger soot mass measured with 406-nm incident light may be related to molecular absorption of large PAH and/or a different dispersion exponent precluding the use of a constant refractive index. Manin et al. [11] discussed this in more detail. 
Returning to Fig. 5, the simulated temporal evolution of the soot volume fraction $\left(f_{\mathrm{v}}\right)$ for Spray A at the central plane of the spray axis from the different ECN participants is presented in the lower five rows of images. It should be noted that the timings represented are relative to fuel injection, which does not account for discrepancies in ignition delay between the experiment and the simulations.

Simulations of the total soot mass as a function of time with higher temporal resolution will be presented later in this work to account for the different ignition delay times.

As was done for the experimental results in Fig. 5, the maximum $f_{\mathrm{v}}$ for the simulations at each time step is indicated in the upper left corner of each false-color image and the upper limit of the displayed color palette is provided in brackets in the lower left corner. Note that the ANL and POL results at $1.7 \mathrm{~ms}$ are presented under the column labeled "1.8 ms" because the results for these two simulations were only provided until $1.7 \mathrm{~ms}$.

Considering the peak simulated $f_{\mathrm{v}}$ at the different timings, the quantity produced initially at $0.9 \mathrm{~ms}$ ASOI by the POL calculations is more than an order of magnitude larger than is observed in the experiments, while that of ANL is around 6-8 times greater than the experiment. The peak $f_{\mathrm{v}}$ in the ETHZ and UW simulations at $0.9 \mathrm{~ms}$ ASOI are within a factor of 2-3 of the experiments; however, the UW result is questionable given that the simulated ignition occurred at $0.82 \mathrm{~ms}$ (see Fig. 2). On the other hand, both of the UNSW simulations show good agreement with the experimental peak $f_{\mathrm{v}}$ at this early timing and captured the experimental ignition delay time for Spray A reasonably well. At the later timings the peak $f_{\mathrm{v}}$ predicted by POL remains high by a factor of 5-6, while the ANL, ETHZ, UNSW, and UW results are within about 1-2 ppm of the experiments.

Although the ANL and POL simulations yield higher than expected peak $f_{\mathrm{v}}$ values, these models best capture the radial extent of the soot field; however, both of these simulations show that the soot field stretches over a longer axial distance, starting closer to the injector than the experiments suggest.

Specifically, the LII and DBIEI measurements, as well as natural luminosity imaging of broadband emission from soot particles, indicate that particulate matter is first observed beyond $30 \mathrm{~mm}$ from the injector tip for the Spray A condition. Planar laser-induced fluorescence images of PAH formation at the Spray A condition also indicate that the formation of these precursors takes place downstream of $30 \mathrm{~mm}$ [57]. The soot observed at more upstream locations in the ANL and POL may thus illustrate a weakness of simplified soot models yielding particulates directly from acetylene.

On the contrary, the ETHZ, UNSW, and UW models better capture the axial extent of the soot field while the radial extent appears too narrow, with the ETHZ CMC model having the widest radial distribution of the three. To understand the reason for the narrow soot field, a comparison of the simulated radial mixture fraction crosssections with radial penetration measurements by high-speed schlieren imaging was considered. The comparison suggested reasonable agreement between the simulated and experimental radial extent of the fuel vapor. Though not shown here, we then considered the simulated distributions of acetylene mass fraction, since all but the UW RANS models use highly simplified soot chemistry forming from acetylene. Indeed, the POL model showed a broader radial distribution of acetylene in the penetrating head compared to the other RANS models. We therefore recommend that further research efforts be directed at understanding why the different RANS models yield such variance in the radial distribution of acetylene and soot.
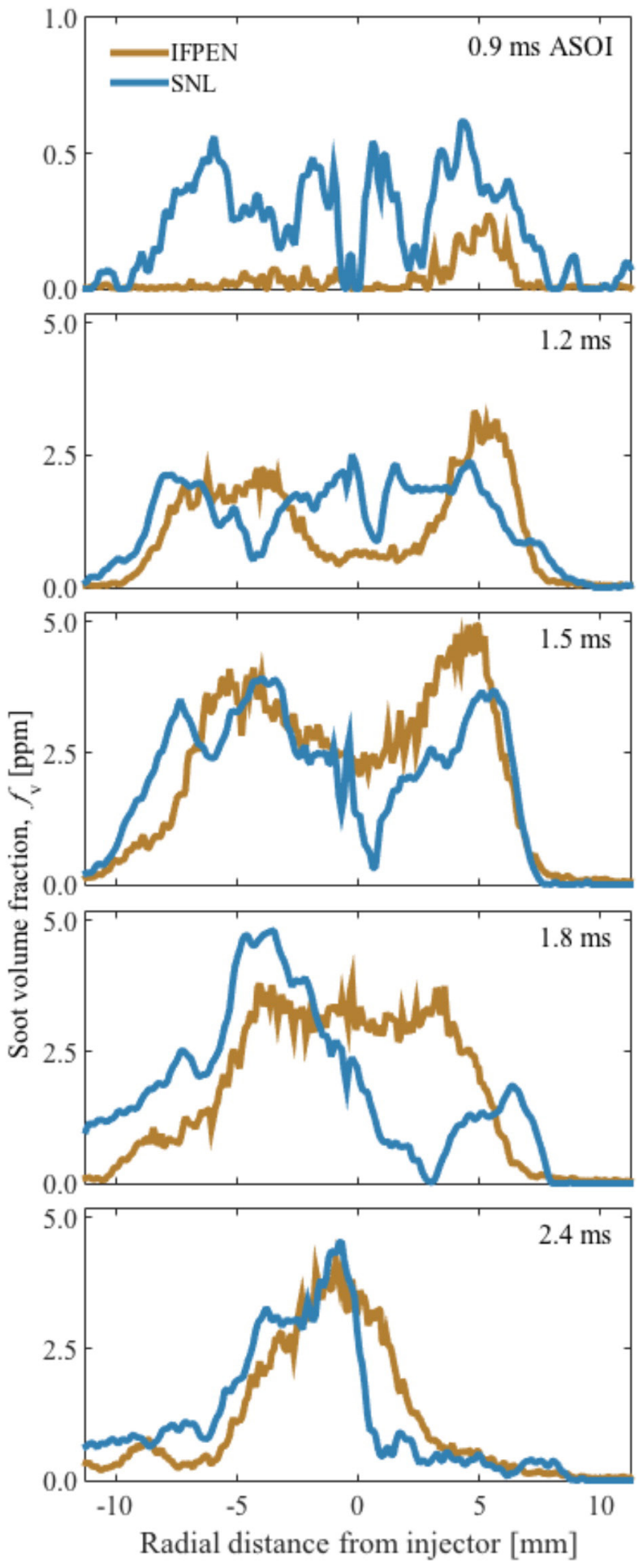

Figure 6. Radial cross-sections of $\mathrm{f}_{\mathrm{v}}$ comparing the IFPEN LII measurements with that determined from the SNL DBIEI measurements after tomographic reconstruction. 


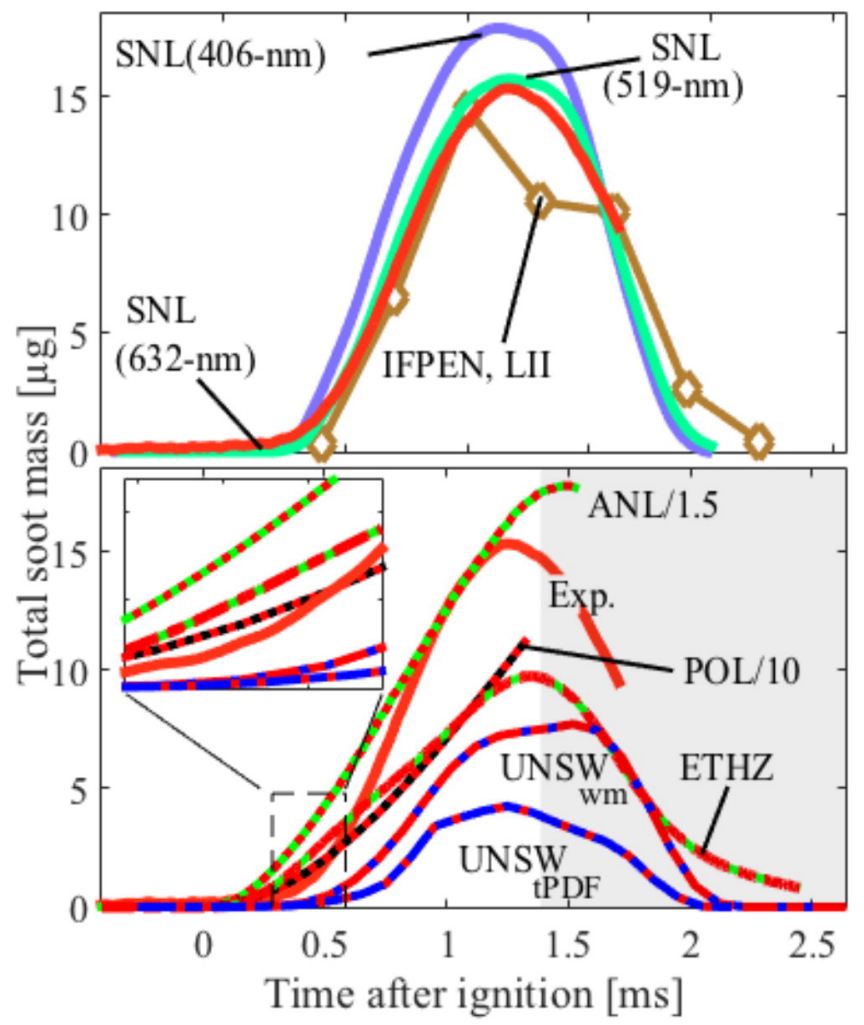

Figure 7. Top panel: Total soot mass within field of view for Spray A (1.5-ms injection duration) as measured by LII (IFPEN) and DBIEI (SNL) using three different incident wavelengths. Bottom panel: Simulated total soot mass along with IFPEN and SNL (632-nm) experimental total soot mass. Note that time is relative to high-temperature ignition.

Whereas a comparison of the temporal evolution of $f_{\mathrm{v}}$ relative to the start of injection showed consistency between the experiments and the majority of the simulations, larger discrepancies are observed when comparing the temporal evolution of the total soot mass as a function of the time after high-temperature ignition. Returning to Fig. $\underline{7}$, the lower panel presents the simulated total soot mass along with the experimental measurements from SNL as a function of time after ignition. All simulations are included in the figure with the exception of UW due to the large inconsistency in ignition delay time mentioned previously. Note that the comparison of the experimental and simulated total soot mass is only valid until approximately $1.4 \mathrm{~ms}$ after ignition, which corresponds to the time that the penetrating head begins to pass out of the field-of-view in the DBIEI experiments as shown in Fig. 5 (1.8 ms ASOI). The region beyond $1.4 \mathrm{~ms}$ in the bottom panel of Fig. 7 is therefore shaded.

Moving along the time axis, the total soot mass in the POL simulation is initially an order of magnitude larger than the experiment (see inset axis). After this initial onset period, the experimental rate of soot mass formation increases reaching a maximum near $0.75 \mathrm{~ms}$ after ignition. While the POL does show an increased rate during this time, the increase relative to the onset period falls short in comparison to the experiment. Finally, we note that the higher soot mass in the POL simulation is presumed to be, at least in part, due to a $20 \%$ greater acetylene mass fraction relative to the other RANS simulations.
The ANL simulation, which has been scaled by a factor of 1.5 , yields soot earlier than the experiments, but the increased rate of soot mass formation after the onset period appears more consistent with the experimental results. The peak total soot mass at the end of the ANL simulation is $26.7 \mu \mathrm{g}$, less than a factor of two larger than the experiments. The timing and quantity of the initial rise in soot mass is best captured by the ETHZ simulation, while the rate of soot mass formation after the initial onset does not increase sufficiently to capture the experimental trend. Although soot onset is quite delayed in the UNSW models, the changing rate of soot mass formation after soot onset is improved over that of the other RANS models. An improved representation of the radial distribution of soot in the ETHZ and UNSW models would undoubtedly aid in better agreement with the experiments.

\section{Quasi-Steady Soot}

Measurements of the quasi-steady soot field at the Spray A condition and a number of parametric variants were performed at IFPEN, SNL, and UPV. For these conditions, quasi-steady behavior begins slightly after $2 \mathrm{~ms}$ ASOI and ends just prior to the end of injection. The comparison of these data provides another opportunity to evaluate the consistency of ECN measurements performed at different institutions. For brevity, we include only the parametric variants in ambient temperature and oxygen concentration for which a comparison among different institutions is possible. For additional parametric variants in temperature and ambient density, the reader is referred to the ECN data archive [됴].

The $f_{\mathrm{v}}$ data from IFPEN for Spray A consist of an ensemble average of 30 PLII images. For each of the parametric variants, 10 images were ensemble averaged. For the SNL data, the high-speed DBIEI diagnostic permits both a time average during the quasi-steady period of the spray as well as an ensemble average of repeated injection events. For each condition, 4-5 repeat experiments were performed and ensemble averaged at SNL.

The radial cross-sections of $f_{\mathrm{v}}$ at select locations from the quasisteady IFPEN PLII data along with those determined after tomographic reconstruction of the SNL extinction images are presented in Fig. 8. The axial distances selected represent the location of peak $f_{\mathrm{v}}$ for the different cases. With the exception of the $13 \% \mathrm{O}_{2}$ case, the IFPEN and SNL data are quite consistent. We note that in all IFPEN cases shown in Fig. 8 the ambient temperature was $30 \mathrm{~K}$ higher than targeted and there is evidence that the fuel mass flow rate was lower than that of the SNL experiments, as was discussed in the previous section. It is also clear that the time averaging available in the high-speed DBIEI measurements aids in producing a smoother and more axisymmetric profile in spite of the fewer repeat experiments relative to the IFPEN measurements.

A final comparison of quasi-steady results showing the axial distribution of $K L$ measured at UPV and SNL is provided in Fig. 9 for the Spray A condition and the $21 \% \mathrm{O}_{2}$ variant. As mentioned above, the SNL measurements were performed in a constant-volume pre-burn chamber with injector \#210370 while the UPV measurements were made in a constant-pressure vessel with injector 
\#210675. We note also that UPV used 450-nm incident light for these extinction measurements, thus the SNL data acquired using 406-nm incident light is plotted for comparison.

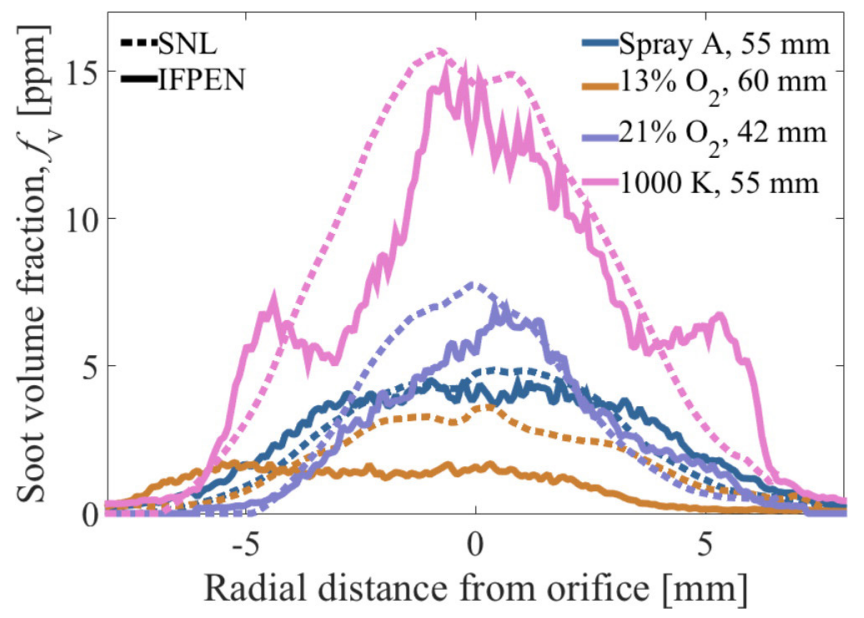

Figure 8. Radial cross-sections of $\mathrm{f}_{\mathrm{y}}$ as measured by IFPEN and SNL during the quasi-steady period of combustion for Spray A and some parametric variants. The select axial locations correspond to the location of peak $f_{v}$ for each case.

The baseline $K L$ of nearly 0.1 in the UPV data upstream of $30 \mathrm{~mm}$ for Spray A and at $20 \mathrm{~mm}$ for the $21 \% \mathrm{O}_{2}$ case suggests that light attenuation by refractive index gradients (i.e., beam steering) may not be sufficiently suppressed by the UPV diffused lighting source.

Subtraction of this offset helps but does not bring the peak $K L$ values into exact agreement. Moreover, while the axial distributions in the $21 \% \mathrm{O}_{2}$ cases are very consistent, the UPV data for Spray A show the peak $K L$ closer to the injector than that of SNL. Considering that the two different injectors used at these institutions have similar flow characteristics, the greater amount of soot in the UPV data might be indicative of a higher ambient temperature. Moreover, for an identical soot-containing medium, one would expect greater extinction in the SNL measurements due to the shorter wavelength of incident light-especially in upstream regions containing immature soot with a lower carbon-to-hydrogen ratio. Increased attenuation at the shorter wavelength may also be possible due to more efficient molecular absorption by PAH.

For the Spray A condition, the peak $K L$ measured by UPV is approximately $25 \%$ greater than that measured by SNL. For reference, we point out that the peak quasi-steady $K L$ for the $1000 \mathrm{~K}$ ambient condition, as measured by SNL, is around two. Based on a simple linear interpolation of the SNL data between $900 \mathrm{~K}$ and 1000 $\mathrm{K}$, a $25 \%$ increase in $K L$ corresponds to a temperature of $925 \mathrm{~K}$. A temperature difference of $25 \mathrm{~K}$ between the UPV and SNL data may be observed in a comparison of the associated ignition delay times and lift-off lengths; however, such measurements specific to these UPV runs are not available. Alternatively, we explored the hypothesis that the UPV ambient temperature in the Spray A DBIEI data may be higher than that of SNL by considering the time to soot onset.

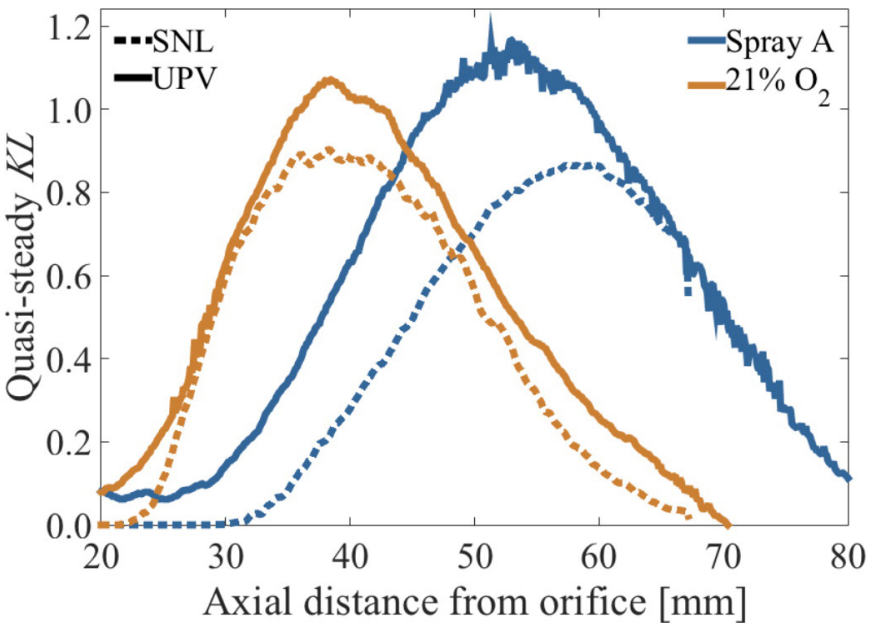

Figure 9. Axial KL distributions from UPV and SNL for the Spray A case and its $21 \%$ ambient $\mathrm{O}_{2}$ variant.

To demonstrate the correlation of soot onset time with ignition delay time, Fig. 10 shows the time required to achieve three different total soot mass quantities as a function of ignition delay time. These data include 10 repeated runs at the Spray A condition. Ignition delay times were determined from high-speed chemiluminescence imaging and confirmed with speed-of-sound corrected pressure measurements. For the three different mass quantities selected, the time required to reach a given threshold increases linearly with increasing ignition delay time from $0.33 \mathrm{~ms}$ up to more than $0.45 \mathrm{~ms}$.

To compare the SNL and UPV soot onset times, the time-resolved axial $K L$ profiles were normalized by the peak mean value displayed in Fig. 9. Soot onset was defined as the time when the normalized instantaneous peak axial $K L$ reached 0.25 . Based on this analysis, soot onset for the Spray A condition occurred at $0.79 \mathrm{~ms}+/-0.02 \mathrm{~ms}$ and $0.75 \mathrm{~ms}$ for the SNL and UPV data, respectively. Based on the data in Fig. 10, at $40 \mu$ s difference in soot onset time corresponds to a difference in ignition delay time of a similar magnitude. Thus, the earlier soot onset time in the UPV Spray A data also suggests a shorter ignition delay time, which can be attributed to a higher ambient temperature. As a final test, a linear interpolation of ignition delay data between $900 \mathrm{~K}$ and $1000 \mathrm{~K}$ suggests that a $25 \mathrm{~K}$ increase above $900 \mathrm{~K}$ would reduce the ignition delay by around $40 \mu \mathrm{s}$.

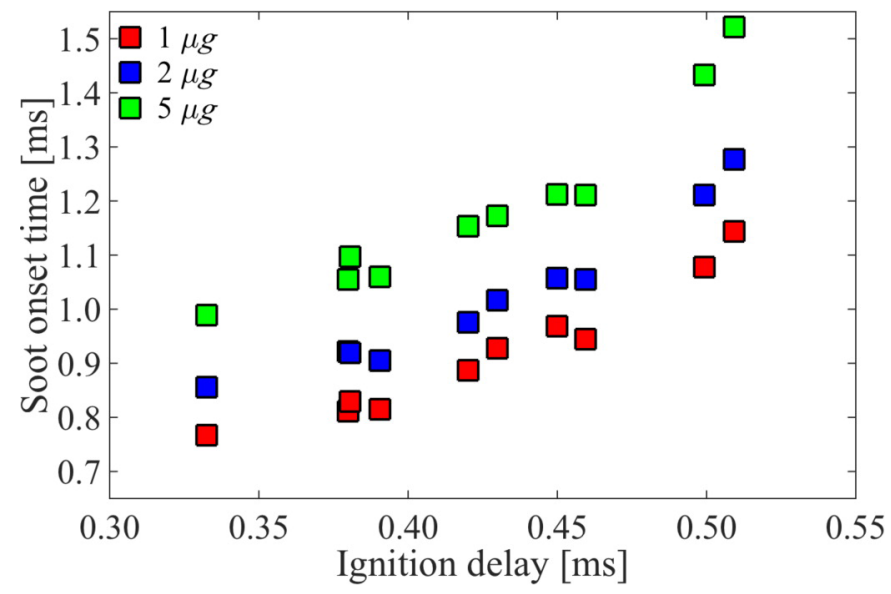

Figure 10. Mass specific soot onset times as a function of ignition delay for 10 repeated Spray A DBIEI experiments at SNL. 


\section{Spray A: Multiple Injections}

The high-speed DBIEI diagnostic was applied at SNL to measure soot transients at the Spray A condition with split $(0.5 / 0.5 \mathrm{dwell} / 0.5$ $\mathrm{ms})$ and pilot/main $(0.3 / 0.5 \mathrm{dwell} / 1.2 \mathrm{~ms})$ injection schedules. Skeen et al. [59] previously investigated the effect of the split injection schedule on mixing and ignition characteristics at the Spray A condition and two lower ambient temperature variants. At the Spray A (900 K ambient) condition, combustion recession occurs following the end of the first injection leaving high-temperature combustion products in the near-nozzle region. As the second injection penetrates, it mixes with these high-temperature products and ignites in approximately half the time required for the first injection to ignite. The local temperature and equivalence ratio at ignition of the second injection are therefore higher leading to a significant increase in soot formation relative to the amount of soot formed by the first $0.5-\mathrm{ms}$ injection. The same combustion recession phenomenon occurs with the pilot/main injection schedule; however, the amount of soot formed during the $0.3-\mathrm{ms}$ injection is below the detection limit of the DBIEI diagnostic.

Four split-injection and three pilot/main experiments were performed at SNL using the DBIEI diagnostic. The ensemble average of the time-resolved total soot mass for the split-injection case is presented in Fig. 11. The shaded region demonstrates the shot-to-shot variation among the four independent experiments. Based on the ensemble average, the second injection produces a factor of four times more soot than the first injection under these conditions. As discussed above, this is mainly attributed to the advanced ignition of the second injection, which occurs near the liquid length where the local equivalence ratio is more fuel rich [59].

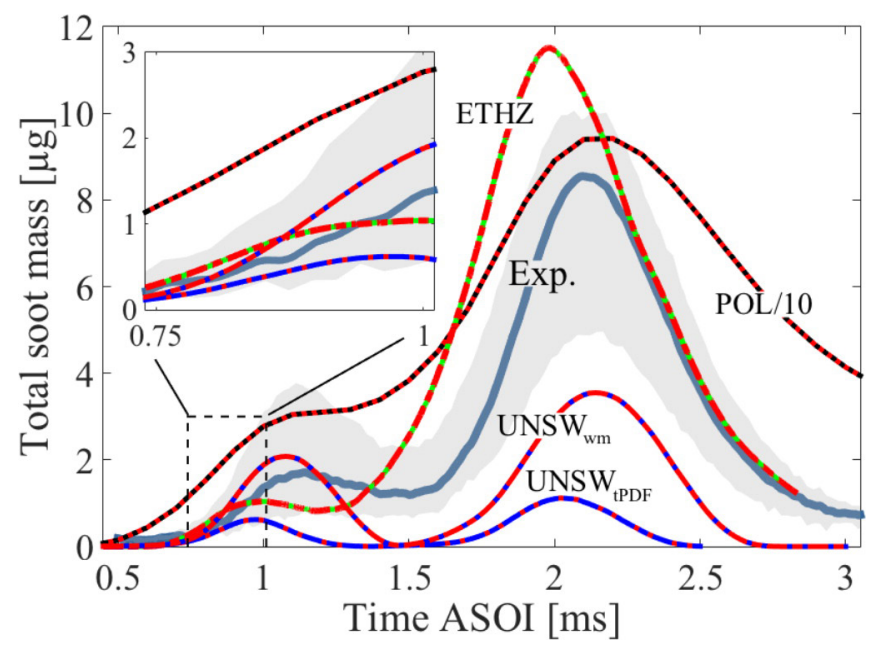

Figure 11. Experimental and simulated total soot mass for split injection schedule $(0.5 / 0.5 \mathrm{dwell} / 0.5 \mathrm{~ms})$ at the Spray A ambient conditions.

It is interesting to consider the ratio of the peak total soot mass formed to the total mass of fuel injected for the single $(1.5 \mathrm{~ms})$ and multiple injection cases. For the single and pilot/main injection schedules, in which equivalent amounts of fuel mass are injected, the total soot mass in both cases reaches a peak value near $15 \mu \mathrm{g}$. Thus, it appears that the pilot/main is neither a benefit nor detriment to soot formation at these specific conditions. Should the pilot injection duration be decreased, there may be a condition in which the pilot does not ignite due to overmixing. This may act to cool the ambient and push the ignition location of the second injection further downstream resulting in less soot.

For the split injection, the total amount of fuel injected is approximately two-thirds of that injected in the single and pilot/main cases. Thought not shown here, the total soot mass for this case peaks near a value of $9 \mu \mathrm{g}$. Thus, the corresponding peak total soot per unit of fuel is not significantly different from the single and pilot/main cases. Had different dwell times between injections been investigated, it is anticipated that a more dramatic change in total soot mass peak would have been observed [으].

The temporal evolution of the simulated total soot mass from four different RANS models is also included in Fig. 11 for comparison. Whereas the RANS based models had difficulty capturing the transient mass peak for the single 1.5-ms injection, two of the models in particular fare much better for the split-injection scenario. As shown in the inset of Fig. 11, the simulated initial rise in soot mass for three out of the four models up to $1 \mathrm{~ms}$ ASOI falls within the shaded region corresponding shot-to-shot variation in the experiments; however, the UNSW well-mixed model and ETHZ CMC model remain more consistent with the experiments at later timings.

While the timing and amplitude of the peak total soot for the first injection is best captured by the UNSW well-mixed model, it appears that oxidation of this initial soot occurs too quickly resulting in a period where no soot is observed during the dwell between injections. This phenomenon may be related to our previous observation that the radial width is too narrow in some of the RANS models for the single-injection case. On the other hand, recall that the ETHZ CMC model, which showed a slightly wider radial distribution for $f_{\mathrm{v}}$ in the single 1.5-ms injection case, does not completely oxidize soot formed from the first injection during the dwell. Despite the ETHZ CMC and UNSW well-mixed results employing the same soot models and reaction constants, differences in soot oxidation rates are seen due to turbulence-chemistry interaction, as discussed in detail in [61]. Finally, considering that the ETHZ CMC model showed substantial improvement for the multiple injection case over the single injection results, we point out that this model was updated to account for multiple injections using an extended method with a single totalmixture-fraction as the conditioning scalar [므].

\section{SUMMARY/CONCLUSIONS}

This work has reviewed and compared experimental and simulated soot data performed in conjunction with the Engine Combustion Network working group. Both new and previously published works have been compiled to provide information on the progress of ECN soot efforts. The main observations are summarized as follows.

Soot particles extracted from Spray A flames for TEM analysis are characterized by a median count primary particle diameter less than $20 \mathrm{~nm}$. Consistent with experiments in laminar diffusion fames at atmospheric pressure, TEM results from the $21 \%$ ambient $\mathrm{O}_{2}$ case show smaller primary particle diameters in the oxidation region near the flame length compared to larger primary particle diameters 
extracted near the soot formation region. Along with a reference refractive index selected for ECN soot measurements, soot morphological properties determined by TEM analysis also provide input parameters for the determination of the wavelength specific dimensionless extinction coefficient via the Rayleigh-Debye-Gans approximation for fractal aggregates. While great uncertainty remains in the true refractive index for soot in high-pressure spray flames, the approach described herein provides a consistent means for comparing ECN soot measurements using different optical diagnostics. The small primary particle size observed in high-pressure spray flames also reduces the error associated with assuming constant aggregate size throughout the flame.

Experimental measurements by IFPEN and SNL of the transient soot volume fraction in Spray A, as well as the quasi-steady soot volume fraction in Spray A and a number of parametric variants, show excellent consistency. This is in spite of the different soot diagnostics applied, different injectors (from the same family of ECN Spray A injectors), different combustion vessels, and a $30 \mathrm{~K}$ difference in the mean measured ambient temperature of the repeated experiments. While the higher temperature at IFPEN alone should lead to increased soot formation, a reduced rate of fuel flow through the IFPEN injector appears to have caused a compensating effect. Measurements of the axial $K L$ profile during quasi-steady combustion by UPV and SNL were more consistent for the $21 \%$ ambient $\mathrm{O}_{2}$ case, with a larger peak $K L$ and more upstream profile measured by UPV for the Spray A baseline condition. A comparison of soot onset times between the two experiments provides strong evidence that the UPV Spray A experiments were characterized by a shorter ignition delay time. This would be a consequence of a higher ambient temperature.

The ability of a variety of engine spray CFD models to capture the temporal evolution of soot in single and multiple-injection scenarios was examined with mixed results. Most models captured the quantitative progression of peak soot volume fraction for the single 1.5-ms injection case, while the LES simulation of ANL and the CMC model of ETHZ fared reasonably well when comparing total soot mass. Unfortunately, an LES simulation of the multiple injection cases is not yet available; however several of the RANS models showed much improvement when comparing the transient total soot mass for the split-injection case. An observation that the RANS models yield radial soot distributions that are narrower than expected based on the experiments must be addressed in future work.

\section{REFERENCES}

1. Meijer, M., et al., "Engine Combustion Network (ECN): Characterization and comparison of boundary conditions for different combustion vessels," Atomization and Sprays 22(9):777-806, 2012, doi:10.1615/AtomizSpr.2012006083.

2. Kastengren, A.L., et al., "Engine combustion network (ECN): measurements of nozzle geometry and hydraulic behavior," Atomization and Sprays 22(12):1011-1052, 2012, doi:10.1615/ AtomizSpr.2013006309.

3. Manin, J., Bardi M., and Pickett L., "Evaluation of the liquid length via diffused back-illumination imaging in vaporizing diesel sprays," presented at COMODIA, Fukuoka, Japan, July 23-26, 2012.

4. Manin, J., Kastengren A., and Payri R., "Understanding the acoustic oscillations observed in the injection rate of a common-rail direct injection diesel injector," Journal of engineering for gas turbines and power 134(12):122801, 2012.
5. Bardi, M., et al., "Engine combustion network: comparison of spray development, vaporization, and combustion in different combustion vessels," Atomization and Sprays 22(10):807-842, 2012, doi:10.1615/ AtomizSpr.2013005837.

6. Siebers, D., "Liquid-Phase Fuel Penetration in Diesel Sprays," SAE Technical Paper 980809, 1998, doi:10.4271/980809.

7. Verhoeven, D., Vanhemelryck, J., and Baritaud, T., "Macroscopic and Ignition Characteristics of High-Pressure Sprays of Single-Component Fuels," SAE Technical Paper 981069, 1998, doi: $\underline{10.4271 / 981069}$.

8. Pickett, L., Genzale, C., Bruneaux, G., Malbec, L. et al., "Comparison of Diesel Spray Combustion in Different High-Temperature, High-Pressure Facilities," SAE Int. J. Engines 3(2):156-181, 2010, doi:10.4271/2010$\underline{01-2106}$

9. Payri, R., et al., "Fuel temperature influence on diesel sprays in inert and reacting conditions," Applied Thermal Engineering 35:185-195, 2012, doi:10.1016/j.applthermaleng.2011.10.027.

10. Cenker, E., Bruneaux, G., Pickett, L., and Schulz, C., "Study of Soot Formation and Oxidation in the Engine Combustion Network (ECN), Spray A: Effects of Ambient Temperature and Oxygen Concentration," SAE Int. J. Engines 6(1):352-365, 2013, doi:10.4271/2013-01-0901.

11. Manin, J., Pickett, L., and Skeen, S., "Two-Color Diffused BackIllumination Imaging as a Diagnostic for Time-Resolved Soot Measurements in Reacting Sprays," SAE Int. J. Engines 6(4):1908-1921, 2013, doi:10.4271/2013-01-2548.

12. Ghandhi, J. and Heim D., "An optimized optical system for backlit imaging," Review of scientific instruments 80(5):056105, 2009.

13. Westlye, F.R., et al., "Diffuse back-light illumination setup for high temporal resolution extinction imaging," Applied Optics 2016, submitted.

14. Cenker, E., et al., "Assessment of soot particle-size imaging with LII at Diesel engine conditions," Applied Physics B 119(4):765-776, 2015.

15. Kook, S. and Pickett L.M., "Soot volume fraction and morphology of conventional and surrogate jet fuel sprays at $1000-\mathrm{K}$ and $6.7-$ MPa ambient conditions," Proceedings of the Combustion Institute 33(2):2911-2918, 2011.

16. Aizawa, T., Nishigai, H., Kondo, K., Yamaguchi, T. et al., "Transmission Electron Microscopy of Soot Particles Directly Sampled in Diesel Spray Flame - A Comparison between US\#2 and Biodiesel Soot," SAE Int. J. Fuels Lubr. 5(2):665-673, 2012, doi:10.4271/2012-01-0695.

17. Xue, Q., et al., "Large eddy simulation of fuel-spray under nonreacting IC engine conditions," 23(10):925-955, 2013, doi:10.1615/ AtomizSpr.2013008320.

18. Luo, Z., et al., "Development and validation of an ndodecane skeletal mechanism for spray combustion applications," Combustion Theory and Modelling 18(2):187-203, 2014, doi:10.1080/13647830.2013.872807.

19. Hiroyasu, H. and Kadota, T., "Models for Combustion and Formation of Nitric Oxide and Soot in Direct Injection Diesel Engines," SAE Technical Paper 760129, 1976, doi:10.4271/760129.

20. Som, S., "Development and validation of spray models for inestigating diesel engine combustion and emissions," Ph.D. thesis, Mechanical Engineering Department, University of Illinois at Chicago, Chicago, 2009.

21. Som, S. and Aggarwal S., "Effects of primary breakup modeling on spray and combustion characteristics of compression ignition engines," Combustion and Flame 157(6):1179-1193, 2010.

22. Senecal, P., Richards, K., Pomraning, E., Yang, T. et al., "A New Parallel Cut-Cell Cartesian CFD Code for Rapid Grid Generation Applied to In-Cylinder Diesel Engine Simulations," SAE Technical Paper 2007-010159, 2007, doi:10.4271/2007-01-0159.

23. Pei, Y., et al., "Large eddy simulation of a reacting spray flame with multiple realizations under compression ignition conditions," Combustion and Flame 162(12):4442-4455, 2016, doi:10.1016/j. combustflame.2015.08.010

24. D'Errico, G., et al., "Comparison of well-mixed and multiple representative interactive flamelet approaches for diesel spray combustion modelling," Combustion Theory and Modelling 18(1)2014.

25. Yao, T., et al., "A reduced model for n-dodecane with optimized semiglobal low-temperature chemistry for diesel engine simulations," Fuel 2015, submitted.

26. Moss, J., Stewart C., and Syed K., "Flowfield modelling of soot formation at elevated pressure," Proceedings of the Combustion Institute 22(1):413-423, 1989.

27. Reitz, R. and Diwakar, R., "Effect of Drop Breakup on Fuel Sprays," SAE Technical Paper $\underline{860469}$, 1986, doi:10.4271/860469. 
28. Wright, Y.M., et al., "Simulations of spray autoignition and flame establishment with two-dimensional CMC," Combustion and Flame 143(4):402-419, 2005.

29. Wright, Y.M., et al., "Experiments and Simulations of n-Heptane Spray Auto-Ignition in a Closed Combustion Chamber at Diesel Engine Conditions," Flow Turbulence and Combustion 84(1):49-78, 2010, doi:DOI 10.1007/s10494-009-9224-0.

30. Bolla, M., Wright Y.M., and Boulouchos K., "Application of a Conditional Moment Closure Combustion model to a large two-stroke marine Diesel engine reference experiment," presented at COMODIA, Fukuoka, Japan, July 23-26, 2012.

31. Bolla, M., Srna, A., Wright, Y., Von Rotz, B. et al., "Influence of Injector Diameter (0.2-1.2 mm range) on Diesel Spray Combustion: Measurements and CFD Simulations," SAE Technical Paper 2014-01$\underline{1419}$, 2014, doi: 10.4271/2014-01-1419.

32. Bolla, M., et al., "Soot Formation Modeling of n-Heptane Sprays Under Diesel Engine Conditions Using the Conditional Moment Closure Approach," Combustion Science and Technology 185(5):766-793, 2013, doi:Doi 10.1080/00102202.2012.752362.

33. Leung, K.M., Lindstedt R.P., and Jones W.P., "A Simplified ReactionMechanism for Soot Formation in Nonpremixed Flames," Combustion and Flame 87(3-4):289-305, 1991.

34. Pope, S.B., "Computationally efficient implementation of combustion chemistry using in situ adaptive tabulation," Combustion Theory and Modelling 1(1):41-63, 1997.

35. Amsden, A., Kiva-3v, Release 2, Improvements to Kiva-3v. 1999, Los Alamos National Laboratory.

36. Wang, B.-L., et al., "A generalized renormalization group turbulence model and its application to a light-duty diesel engine operating in a low-temperature combustion regime," International Journal of Engine Research 14(3):279-292, 2013, doi:10.1177/1468087412465379.

37. Reitz, R.D., "Modeling atomization processes in high-pressure vaporizing sprays," Atomisation Spray Technology 3:309-337, 1987.

38. Patterson, M. and Reitz, R., "Modeling the Effects of Fuel Spray Characteristics on Diesel Engine Combustion and Emission," SAE Technical Paper 980131, 1998, doi:10.4271/980131.

39. Wang, H., et al., "Development of a reduced n-dodecane-PAH mechanism and its application for n-dodecane soot predictions," Fuel 136:25-36, 2014, doi:10.1016/i.fuel.2014.07.028.

40. Vishwanathan, G. and Reitz R.D., "Development of a Practical Soot Modeling Approach and Its Application to Low-Temperature Diesel Combustion," Combustion Science and Technology 182(8):1050-1082, 2010, doi:10.1080/00102200903548124.

41. Wang, H., et al., "Development of an n-heptane-nbutanol-PAH mechanism and its application for combustion and soot prediction," Combustion and Flame 160(3):504-519, 2013.

42. Pope, S., "PDF methods for turbulent reactive flows," Progress in Energy and Combustion Science 11(2):119-192, 1985.

43. Chishty, M., Bolla, M., Pei, Y., Hawkes, E. et al., "Soot Formation Modelling of Spray-A Using a Transported PDF Approach," SAE Technical Paper 2015-01-1849, 2015, doi:10.4271/2015-01-1849.

44. Pei, Y., et al., "Modelling n-dodecane spray and combustion with the transported probability density function method," Combustion and Flame 162(5):2006-2019, 2015.

45. Pickett, L., Manin, J., Genzale, C., Siebers, D. et al., "Relationship Between Diesel Fuel Spray Vapor Penetration/Dispersion and Local Fuel Mixture Fraction," SAE Int. J. Engines 4(1):764-799, 2011, doi: 10.4271/2011-01-0686.

46. Smyth, K.C. and Shaddix C.R., "The elusive history of $\mathrm{m} \sim=1.57-0.56 \mathrm{i}$ for the refractive index of soot," Combustion and Flame 107(3):314-320, 1996.

47. Bond, T.C. and Bergstrom R.W., "Light absorption by carbonaceous particles: An investigative review," Aerosol science and technology 40(1):27-67, 2006.

48. Williams, T.C., et al., "Measurement of the dimensionless extinction coefficient of soot within laminar diffusion flames,"International Journal of Heat and Mass Transfer 50(7):1616-1630, 2007.

49. Nishigai, H., et al., "Morphology of JIS\# 2 and Fischer Tropsch Diesel (FTD) Soot Tropsch Diesel (FTD) Soot in Spray Flames via Transmission Electron Microscopy (TEM)," presented at COMODIA, Fukuoka, Japan, July 23-26, 2012.

50. Li, Z., et al., "Evolution of the nanostructure, fractal dimension and size of in-cylinder soot during diesel combustion process," Combustion and Flame 158(8):1624-1630, 2011.
51. Kholghy, M., et al., "The evolution of soot morphology in a laminar coflow diffusion flame of a surrogate for Jet A-1," Combustion and Flame 160(10):2119-2130, 2013, doi:10.1016/i. combustflame.2013.04.008.

52. Kook, S. and Pickett, L., "Soot Volume Fraction and Morphology of Conventional, Fischer-Tropsch, Coal-Derived, and Surrogate Fuel at Diesel Conditions," SAE Int. J. Fuels Lubr. 5(2):647-664, 2012, doi:10.4271/2012-01-0678.

53. Köylü, Ü.Ö., et al., "Simultaneous measurements of soot volume fraction and particle size/microstructure in flames using a thermophoretic sampling technique," Combustion and Flame 110(4):494-507, 1997.

54. Dalzell, W. and Sarofim A., "Optical constants of soot and their application to heat-flux calculations," Journal of Heat Transfer 91(1):100-104, 1969.

55. Manin, J., Skeen, S., Pickett, L., Kurtz, E. et al., "Effects of Oxygenated Fuels on Combustion and Soot Formation/ Oxidation Processes," SAE Int. J. Fuels Lubr. 7(3):704-717, 2014, doi:10.4271/2014-01-2657.

56. Malbec, L., Egúsquiza, J., Bruneaux, G., and Meijer, M., "Characterization of a Set of ECN Spray A Injectors: Nozzle to Nozzle Variations and Effect on Spray Characteristics," SAE Int. J. Engines 6(3):1642-1660, 2013, doi:10.4271/2013-24-0037.

57. Skeen, S.A., Manin J., and Pickett L.M., "Simultaneous formaldehyde PLIF and high-speed schlieren imaging for ignition visualization in high-pressure spray flames," Proceedings of the Combustion Institute 35(3):3167-3174, 2014, doi:10.1016/j.proci.2014.06.040.

58. "Engine Combustion Network Data Archive," http://www.sandia.gov/ ecn/cvdata/dsearch/frameset.php, accessed Oct. 2015

59. Skeen, S., Manin, J., and Pickett, L., "Visualization of Ignition Processes in High-Pressure Sprays with Multiple Injections of n-Dodecane," SAE Int. J. Engines 8(2):696-715, 2015, doi:10.4271/2015-01-0799.

60. Bruneaux, G. and Maligne, D., "Study of the Mixing and Combustion Processes of Consecutive Short Double Diesel Injections," SAE Int. J. Engines 2(1):1151-1169, 2009, doi:10.4271/2009-01-1352.

61. Bolla, M., et al., "Influence of turbulence-chemistry interaction for n-heptane spray combustion under diesel engine conditions with emphasis on soot formation and oxidation," Combustion Theory and Modelling 18(2):330-360, 2014.

62. Bolla, M., et al., "An Extended CMC Model for the Simulation of Diesel Engines with Multiple Injections," presented at International Multidimensional Engine Modeling Users' Group Meeting, Detroit, Michigan, April 7, 2014.

\section{CONTACT INFORMATION}

Corresponding author contact information:

Scott A. Skeen

sskeen@sandia.gov

\section{ACKNOWLEDGMENTS}

The following individuals and funding agencies are acknowledged for their support.

The authors from DTU acknowledge the Technical University of Denmark, Danish Strategic Research Council, and MAN Diesel \& Turbo

University of Wisconsin: Financial support provided by the Princeton Combustion Energy Frontier Research Center.

ETH Zurich: Financial support from the Swiss Federal Office of Energy (grant no. SI/500818-01) and the Swiss Competence Center for Energy and Mobility (CCEM project "In-cylinder emission reduction") is gratefully acknowledged. 
Argonne National Labs: Work was funded by U.S. DOE Office of Vehicle Technologies, Office of Energy Efficiency and Renewable Energy under Contract No. DE-AC02-06CH11357. We also gratefully acknowledge the computing resources provided on Fusion, a computing cluster operated by the Laboratory Computing Resource Center at Argonne National Laboratory.

Sandia National Labs, Combustion Research Facility: Work was supported by the U.S. Department of Energy, Office of Vehicle Technologies. Sandia is a multiprogram laboratory operated by Sandia Corporation, a Lockheed Martin Company, for the United
States Department of Energy's National Nuclear Security Administration under contract DEAC04-94AL85000. Chris Carlen and Dave Cicone are gratefully acknowledged for technical assistance.

The authors from ANL and SNL also wish to thank Gurpreet Singh and Leo Breton, program managers at U.S. DOE, for their support.

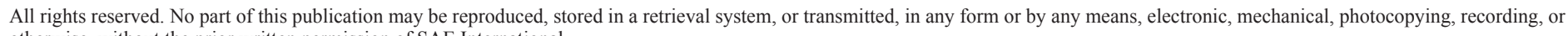
otherwise, without the prior written permission of SAE International.

Positions and opinions advanced in this paper are those of the author(s) and not necessarily those of SAE International. The author is solely responsible for the content of the paper. 